\title{
Reactions of Alkaline Earth Metal Ions with Methanol Clusters
}

\author{
Wenyun Lu and Shihe Yang* \\ Department of Chemistry, Hong Kong University of Science and Technology, Clear Water Bay, \\ Kowloon, Hong Kong
}

Received: September 4, 1997; In Final Form: October 21, 1997

\begin{abstract}
The gas phase reactions between singly charged alkaline earth metal ions $\left(\mathrm{Mg}^{+}, \mathrm{Ca}^{+}, \mathrm{Sr}^{+}\right.$and $\left.\mathrm{Ba}^{+}\right)$and methanol clusters are studied in a pick-up cluster source. In much the same way as for the alkaline earth metal ion-water cluster systems studied by Fuke et al. (J. Am. Chem. Soc. 1995, 117, 747), anomalous product distributions were observed that are characterized by two product switching regions. The first product switching from $\mathrm{M}^{+}\left(\mathrm{CH}_{3} \mathrm{OH}\right)_{n}$ to $\mathrm{MOCH}_{3}{ }^{+}\left(\mathrm{CH}_{3} \mathrm{OH}\right)_{n-1}$ occurs for $n$ at around 5. The $\mathrm{MOCH}_{3}{ }^{+}\left(\mathrm{CH}_{3} \mathrm{OH}\right)_{n-1}$ species switches back to $\mathrm{Mg}^{+}\left(\mathrm{CH}_{3} \mathrm{OH}\right)_{n}$ for $n$ at around 15 (second switching). The critical sizes for the first and the second switching were found to be affected by the metal and deuterium substitutions. Ab initio calculations on the structures and energetics of the reactants and products were carried out to facilitate the interpretation of the product switching behaviors.
\end{abstract}

\section{Introduction}

The study of metal ion-solvent cluster $\left(\mathrm{M}^{+}-\mathrm{S}_{n}\right)$ reactions provides valuable information on their reactivity patterns with increasing cluster size, reflecting the transition from gas-phase reactions to solution phase reactions. While research on the reactions of metal ions with molecules is abundant, studies on reactions of molecular clusters with metal ions have been scarce. In general, reactions of alkaline earth metal ions with solvent molecular clusters lead to the association products (e.g., $\left.\mathrm{Mg}^{+}\left(\mathrm{CO}_{2}\right)_{n}\right) .{ }^{1}$ However, unusual size-dependent reaction patterns may occur for some solvent clusters. Interesting examples are the reactions between $\mathrm{Mg}^{+}, \mathrm{Ca}^{+}$, and water clusters studied by Fuke's group. ${ }^{2-4}$ The most intriguing finding from their experiments is that the association products $\mathrm{M}^{+}\left(\mathrm{H}_{2} \mathrm{O}\right)_{n}(\mathrm{M}=$ $\mathrm{Mg}$ and $\mathrm{Ca}$ ) are unstable against $\mathrm{H}$-elimination when the clusters reach a certain size. For example, $\mathrm{Mg}^{+}\left(\mathrm{H}_{2} \mathrm{O}\right)_{n}$ change to $\mathrm{MgOH}^{+}\left(\mathrm{H}_{2} \mathrm{O}\right)_{n-1}$ for $n \geq 6$ (first switching). In addition, the H-elimination product switches back to $\mathrm{Mg}^{+}\left(\mathrm{H}_{2} \mathrm{O}\right)_{n}$ for $n \geq 15$ (second switching). Similar product distributions were observed for $\mathrm{Ca}^{+}-\mathrm{H}_{2} \mathrm{O}$, though the exact switching points differ slightly. ${ }^{3}$

To understand the reactions of $\mathrm{M}^{+}\left(\mathrm{H}_{2} \mathrm{O}\right)_{n}(\mathrm{M}=\mathrm{Mg}$ and $\mathrm{Ca})$, Iwata and co-workers performed ab initio molecular orbital calculations ${ }^{5,6}$ on these cluster ions and their corresponding dehydrogenation products, $\mathrm{MOH}^{+}\left(\mathrm{H}_{2} \mathrm{O}\right)_{n-1}$, with $n$ as large as 8 (for $\mathrm{Ca}^{+}$). The two species were found to have very different structures. For instance, the first solvation shell of $\mathrm{Mg}^{+}\left(\mathrm{H}_{2} \mathrm{O}\right)_{n}$ is filled with three water molecules and the fourth water molecule starts to fill the second shell. On the other hand, in $\mathrm{MgOH}^{+}\left(\mathrm{H}_{2} \mathrm{O}\right)_{n}$, all the water molecules are directly bonded to $\mathrm{Mg}^{+}$for $n \geq 6$. The hydration energy of $\mathrm{MgOH}^{+}$is much larger than that of $\mathrm{Mg}^{+}$because of the strongly polarized $\mathrm{MgOH}^{+}$ core. As a consequence, the products in the reaction become more stable than the reactants with increasing cluster size. The energy change upon hydrogen elimination of $\mathrm{Mg}^{+}\left(\mathrm{H}_{2} \mathrm{O}\right)_{n}$ is positive for $n=1-5$, but becomes negative for $n=6$, a result which is in good agreement with the observed first product switching.

* To whom correspondence should be addressed. E-mail address: chsyang@usthk.ust.hk.
These studies raised an interesting question as to whether such an anomalous cluster reaction would occur in other solvent clusters (e.g., $\mathrm{CH}_{3} \mathrm{OH}$ ). Investigation of other alkaline earth metal ion-solvent cluster systems may provide valuable information regarding the reaction mechanism. In particular, the substitution of one $\mathrm{H}$ in $\mathrm{H}_{2} \mathrm{O}$ by a $\mathrm{CH}_{3}$ group may help to understand the $\mathrm{H}$-elimination behavior of $\mathrm{M}^{+}\left(\mathrm{H}_{2} \mathrm{O}\right)_{n}$. On the basis of this consideration, we have systematically studied the reactions of four alkaline earth metal ions $\left(\mathrm{Mg}^{+}, \mathrm{Ca}^{+}, \mathrm{Sr}^{+}\right.$, and $\mathrm{Ba}^{+}$) with methanol clusters using a pick-up technique. The substitution of $\mathrm{H}$ by a more bulky $\mathrm{CH}_{3}$ group is expected to alter the structure of $\left(\mathrm{H}_{2} \mathrm{O}\right)_{n}$ substantially. In neat liquid, the nature of the hydrogen-bond structure is quite different for water and methanol. Water forms a three-dimensional, tetrahedralbased network such as ice, while methanol forms chains involving about six methanol molecules, on average. ${ }^{7,8}$ As such, the substitution of $\mathrm{H}$ by $\mathrm{CH}_{3}$ offers an opportunity to investigate the structural effects of the molecular clusters on their reactions with alkaline earth metal ions. It would also be interesting to see whether $\mathrm{H}$-elimination or $\mathrm{CH}_{3}$-elimination is the dominant process.

There have been several reports regarding alkaline earth metal ion-methanol clusters with relatively small cluster size. Freisers' group measured the binding energy of $\mathrm{Mg}^{+}$-methanol complex using Fourier transform mass spectrometry (FTMS) combined with the photodissociation technique, and obtained a value of $61 \pm 5 \mathrm{kcal} / \mathrm{mol}{ }^{9}$ Theoretical calculations by Bauschlicher and co-workers on $\mathrm{Mg}^{+}\left(\mathrm{CH}_{3} \mathrm{OH}\right)_{n}(n=1$ and 2$)$ showed that $\mathrm{Mg}^{+}$ion is bonded to the oxygen atoms of the methanol molecules and that the bond is electrostatic in nature. ${ }^{10,11}$ The calculated binding energy for $\mathrm{Mg}^{+}-$methanol is $41 \pm 5 \mathrm{kcal} / \mathrm{mol}$, which is smaller than the experimental result. It was argued that the value from the photodissociation experiment by Freisers et al. corresponds to an upper bound that is much larger than the true binding energy. Duncan and co-workers also performed photodissociation experiments on the $\mathrm{Mg}^{+}-\mathrm{CH}_{3} \mathrm{OH}$ complex. ${ }^{1}$ Unlike the earlier report by Freiser et al., ${ }^{9}$ who found $\mathrm{Mg}^{+}$to be the only ionic product, these authors observed several dissociation channels leading to 
the formation of $\mathrm{Mg}^{+}, \mathrm{CH}_{3}{ }^{+}, \mathrm{MgO}^{+}$, and $\mathrm{MgOH}^{+}$. The last product is difficult to ascertain because of the overlap of the isotope peaks of ${ }^{25} \mathrm{Mg}$ and ${ }^{26} \mathrm{Mg}$ in the mass spectrum. Farrar and co-workers studied $\mathrm{Sr}^{+}\left(\mathrm{CH}_{3} \mathrm{OH}\right)$ and $\mathrm{Sr}^{+}\left(\mathrm{CH}_{3} \mathrm{OD}\right)$ using the photodissociation method. ${ }^{12}$ They observed both the $\mathrm{SrOH}^{+}$ $\left(\mathrm{SrOD}^{+}\right)$formation channel and the ligand loss channel leading to $\mathrm{Sr}^{+}$. Another dissociation channel corresponding to the $\mathrm{SrOCH}_{3}{ }^{+}$formation was not observed. For clusters as large as $\mathrm{Sr}^{+}\left(\mathrm{CH}_{3} \mathrm{OH}\right)_{4}$, the situation is essentially similar except that the large cluster size results in many possible dissociation products. ${ }^{13}$ It was found that disscociation to solvated $\mathrm{SrOH}^{+}$yields precedence to the simple ligand loss channel with increasing cluster size.

Early studies concerning the reactions of alkaline earth metal ions with small methanol clusters have also been reported. Sato and co-workers studied the reaction of $\mathrm{Mg}^{+}$with methanol clusters using the "laser ablation-molecular beam" method. ${ }^{14}$ Only the molecular addition products, however, were identified. In a flow-tube reaction studied by Castleman et al., successive solvation products were observed without dehydrogenation up to $\mathrm{Mg}^{+}\left(\mathrm{CH}_{3} \mathrm{OH}\right)_{6} \cdot{ }^{15}$ Larger clusters were not produced in a significant amount. Very recently, Stace and co-workers reported the gas-phase chemistry of $\mathrm{Mg}^{+}$and $\mathrm{Mg}^{2+}$ in association with methanol clusters using electron impact ionization. ${ }^{16}$ They observed ion signals corresponding to $\mathrm{Mg}^{+}\left(\mathrm{CH}_{3} \mathrm{OH}\right)_{n}$ and $\left[\mathrm{Mg}\left(\mathrm{CH}_{3} \mathrm{OH}\right)_{n}\right]^{2+}$ for $n$ in the range 1-20. They also observed $\mathrm{MgOCH}_{3}{ }^{+}\left(\mathrm{CH}_{3} \mathrm{OH}\right)_{n-1}$ starting at $n=3$ and ascribed it to the reaction products from $\mathrm{Mg}^{+}\left(\mathrm{CH}_{3} \mathrm{OH}\right)_{n}$. It should be pointed out that their experiment is quite different from ours as well as those of Fuke's group in the sense that significant electronic excitation may be involved in the electron impact ionization process.

In this article, we present the results of our experimental and theoretical investigation of the alkaline metal ion-methanol cluster systems. We first describe the experimental setup and computational method. The experimental as well as computational results are then presented. Next, we discuss various aspects of the reactions between alkaline earth metal ions with methanol clusters with the focus on the first and second product switchings observed in the mass spectra. Finally, a summary is given in the end.

\section{Experimental Methods}

The experiments were performed using a pick-up cluster ion source coupled with a reflectron time-of-flight mass spectrometer (RTOFMS). ${ }^{17}$ Metal or metal oxides were mounted on a sample load lock, which was placed $9 \mathrm{~mm}$ downstream from a pulsed valve (R. M. Jordan) as shown in Figure 1a. The pulsed valve was used to generate the methanol cluster beam by supersonic expansion of a gas mixture of methanol vapor seeded in He with a back pressure of 7 atm through a $0.5 \mathrm{~mm}$ nozzle. The $\mathrm{XeCl}$ excimer laser beam was weakly focused on the sample with a flux of $\sim 5 \times 10^{7} \mathrm{~W} / \mathrm{cm}^{2}$. The laser-ablated metal ions perpendicularly crossed the expansion stream $10 \mathrm{~mm}$ from the ablation target where they reacted with the methanol clusters. The products were collimated with a $1 \mathrm{~mm}$ skimmer, and traveled $15 \mathrm{~cm}$ downstream to the extraction region of the RTOFMS. The product cations were extracted by a pulsed high voltage $(950 \mathrm{~V})$ and traveled along the field-free flight tube. The accelerated ions were reflected by a double-stage electric field at the end of the flight tube and detected by a microchannel plate detector (MCP). The source chamber and flight tube were differentially pumped by 10 and 6 in. diffusion pumps (Varian), respectively. The operating pressure was $3 \times 10^{-6}$ Torr for the source chamber and $2 \times 10^{-7}$ Torr for the flight tube.
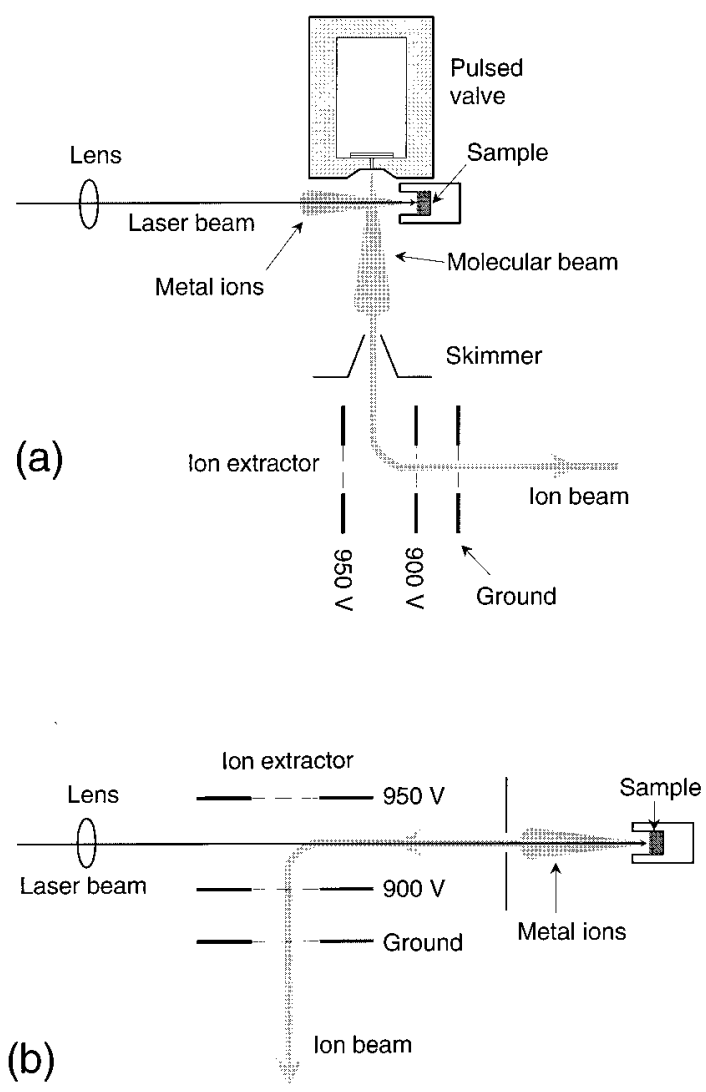

Figure 1. Schematic diagrams of the experimental setup for (a) the study of the reactions between singly charged alkaline earth metal ions with methanol clusters and (b) the measurement of the kinetic energies for the laser-ablated metal ions.

The gas mixture of methanol-He was formed by bubbling the helium gas at a pressure of 7 atm through a methanol liquid reservoir. The pressure of methanol vapor in the gas mixture was estimated to be 127 Torr. An HPLC grade methanol sample (99.9\% purity) was obtained from Fisher Scientific. For deuterium-substitution experiments, $\mathrm{CH}_{3} \mathrm{OD}$ (Aldrich, $+99.5 \%$ D), $\mathrm{CD}_{3} \mathrm{OH}(\mathrm{RDH}, 99 \% \mathrm{D})$, and $\mathrm{CD}_{3} \mathrm{OD}(\mathrm{ACROS}, 100 \% \mathrm{D})$ were used. All the samples were used without further purification. For the deuterated samples, a possible problem was the quick D/H exchange with the residual hydrogen species present in the nozzle system. Great care was taken when loading these samples to the reservoir to avoid contamination. The transfers of these samples were conducted under helium atmosphere in an AtmosBag (Aldrich).

A typical experiment started with the opening of the pulsed valve, followed by the firing of the ablation laser. The extraction high voltage was applied about $100 \mu$ s later. The delay times between the nozzle opening, the laser firing, and the ion extraction were adjusted to obtain the maximum signal intensities. The mass spectra were usually accumulated for 100 laser shots to increase the signal-to-noise ratio. We expect that the methanol cluster formation was largely quenched after expansion through the $8 \mathrm{~mm}$ distance (16 nozzle diameters) to the reaction region. Under a typical source condition, threebody collisions can be quenched in a few nozzle diameters for an axisymmetric expansion, while two-body collisions can remain in an extended length scale. ${ }^{18}$ Therefore, the reaction of metal cations with methanol clusters could be separated from the cluster formation process.

The cluster ion intensities were found to decrease quickly with increasing cluster size. To observe the large cluster ions, a pulsed high voltage was applied to two parallel metal plates 
inside the flight tube. These plates served as a mass gate to deflect unwanted ions. The mass gate was operated in such a way that, under normal conditions, the high voltage was always on except when the cluster ions of interest pass through the gate. A typical high-voltage setting for the mass gate was 800 $\mathrm{V}$. By varying the pulse width and delay time, the mass spectra of different TOF regions could be obtained. Clusters containing as large as 25 methanol molecules were observed under typical experimental conditions.

We also measured kinetic energies of the laser-ablated metal ions. Figure $1 \mathrm{~b}$ shows the setup for the ion kinetic energy measurements. The metal or metal oxide samples were attached to a sample mount on a load lock. The distance between the sample and the center of the ion extraction plates was adjusted to $15 \mathrm{~cm}$. The laser energy and focusing conditions were kept the same as those in the reaction experiments. The pulsed laser irradiation of the sample generates a plume of neutral and ionic species. The ions then flew toward the ion extraction plates. When the ions traveled near the center of the ion extractor, a pulsed high voltage was applied to the plates. The ions were directed by the electric field along the flight tube and detected by the RTOFMS. To measure the kinetic energies of the metal ions, the delay time between the laser pulse and the ion extraction pulse was varied while monitoring the metal ion signal. The plot of the metal ion intensity versus delay time gave the kinetic energy distribution of the laser-ablated metal ions.

\section{Computation Methodology}

Since a qualitative idea of the relative stability of the two species is of primary interest, we performed ab initio calculations at the SCF level with the electron correlation being ignored. This is probably reasonable, because an accurate description of the electrostatic interactions in the metal-ion system depends more on the completeness of the one-particle basis set than on the level of correlation treatment as pointed out by Bauschlicher et al. ${ }^{19}$ The geometries of the singly charged magnesium ionmethanol clusters, $\mathrm{Mg}^{+}\left(\mathrm{CH}_{3} \mathrm{OH}\right)_{n}(n=1-5)$, were optimized with the unrestricted Hartree-Fock self-consistent-field (UHF$\mathrm{SCF}$ ) method as $\mathrm{Mg}^{+}$has an open-shell structure with a single $3 \mathrm{~s}$ valence electron. The corresponding $\mathrm{H}$-elimination cluster ions $\mathrm{MgOCH}_{3}{ }^{+}\left(\mathrm{CH}_{3} \mathrm{OH}\right)_{n-1}(n=1-5)$ were optimized with the closed-shell restricted Hartree-Fock self-consistent-field (RHF-SCF) methods. In all cases, the optimized geometries were obtained by varying all the geometric parameters.

The calculations were performed on a Silicon Graphics workstation using the Gaussion 94 package. $^{20}$ The basis set 6-31G* was used. Natural charge distributions were obtained by performing natural bond orbital (NBO) calculation ${ }^{21}$ using the optimized geometry. Frequency calculations were also performed for the most stable isomers to obtain zero-point vibration (ZPV) energy corrections.

\section{Experimental Results}

1. Metal Ion Kinetic Energy. Laser-ablation of magnesium metal and calcium oxides generates $\mathrm{Mg}^{+}$and $\mathrm{Ca}^{+}$as the predominant ion signals. Figure $2 \mathrm{a}$ shows the intensity of the $\mathrm{Mg}^{+}$signal as a function of the delay time between the laser pulse and the ion extraction pulse at a laser fluence of $5 \times 10^{7}$ $\mathrm{W} / \mathrm{cm}^{2}$. The $\mathrm{Mg}^{+}$ions were detected at delay times between 9 $\mu \mathrm{s}$ and $27 \mu \mathrm{s}$. Since the travel distance is $15 \mathrm{~cm}$, the velocities of these ions are estimated to be between $1.7 \times 10^{6}$ and $5.6 \times$ $10^{5} \mathrm{~cm} / \mathrm{s}$. The resulting kinetic energies of $\mathrm{Mg}^{+}$range from 3.8 to $35 \mathrm{eV}$. The peak ion intensity is at a delay time of $18 \mu \mathrm{s}$
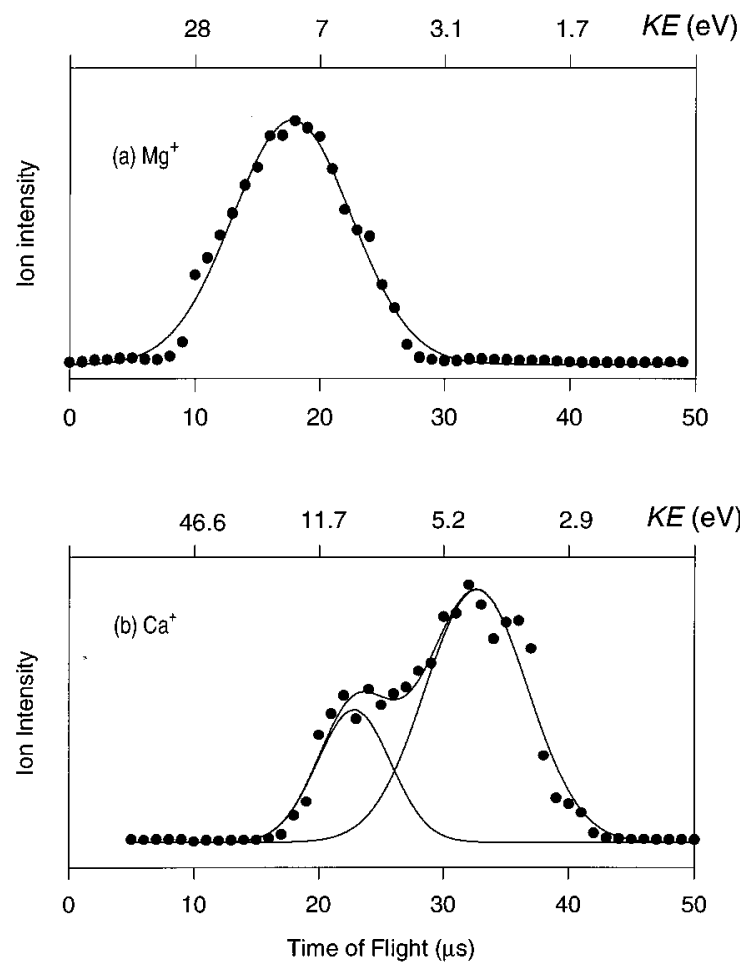

Figure 2. Kinetic energy distributions of the laser-ablated metal ions: (a) $\mathrm{Mg}^{+}$(b) $\mathrm{Ca}^{+}$. The kinetic energy is estimated from the delay time between the laser pulse and the ion extraction pulse. The solid lines are the fittings to the Gaussian function.

based on the fitting. This corresponds to a velocity of $8.3 \times$ $10^{5} \mathrm{~cm} / \mathrm{s}$ and a kinetic energy of $8.6 \mathrm{eV}$.

Figure $2 \mathrm{~b}$ shows the same plot for $\mathrm{Ca}^{+}$at a laser fluence of $5 \times 10^{7} \mathrm{~W} / \mathrm{cm}^{2}$. Most of the $\mathrm{Ca}^{+}$signals were detected between the delay times of $18 \mu \mathrm{s}$ and $41 \mu \mathrm{s}$. This translates to a velocity range from $8.3 \times 10^{5}$ to $3.7 \times 10^{5} \mathrm{~cm} / \mathrm{s}$ and a kinetic energy range from 2.8 and $14.4 \mathrm{eV}$. The Gaussian fitting of the data reveals the existence of two kinds of $\mathrm{Ca}^{+}$ions. The origin of the two peaks is unknown, but we note that this phenomenon was observed for other laser-ablated metal ions such as $\mathrm{Cu}^{+}$ from $\mathrm{Y}_{1} \mathrm{Ba}_{2} \mathrm{Cu}_{3} \mathrm{O}_{x}$ and was found to be related to the laser fluence. ${ }^{22}$ From the fitting in Figure $2 b$, the maximum $\mathrm{Ca}^{+}$ intensity is at a delay time of $32 \mu \mathrm{s}$, which corresponds to a velocity of $4.7 \times 10^{5} \mathrm{~cm} / \mathrm{s}$ and a kinetic energy of $4.6 \mathrm{eV}$. The measurements of kinetic energy distribution of $\mathrm{Sr}^{+}$and $\mathrm{Ba}^{+}$ from laser ablation of $\mathrm{SrO}$ and $\mathrm{BaO}$ yielded similar results.

2. Reactions between Alkaline Earth Metal Ions and Methanol Clusters. 2.1. Reaction between $\mathrm{Mg}^{+}$and Methanol Clusters. Typical TOF mass spectra of the reaction products between $\mathrm{Mg}^{+}$and methanol clusters are displayed in Figure 3. In the mass spectrum in Figure $3 \mathrm{a}, \mathrm{Mg}^{+}$and its complexes with methanol clusters can be readily identified due to the characteristic isotope distribution of $\mathrm{Mg}\left({ }^{24} \mathrm{Mg}, 78.99 \% ;{ }^{25} \mathrm{Mg}, 10.00 \%\right.$; and $\left.{ }^{26} \mathrm{Mg}, 11.01 \%\right) .{ }^{23}$ Hereafter, the $\mathrm{Mg}$ we refer to is the most abundant ${ }^{24} \mathrm{Mg}$ isotope. Presumably, the cluster ions $\mathrm{Mg}^{+}\left(\mathrm{CH}_{3} \mathrm{OH}\right)_{n}$ stem from the association reaction between $\mathrm{Mg}^{+}$and methanol clusters:

$$
\begin{gathered}
\mathrm{Mg}^{+}+\left(\mathrm{CH}_{3} \mathrm{OH}\right)_{m} \rightarrow\left[\mathrm{Mg}^{+}\left(\mathrm{CH}_{3} \mathrm{OH}\right)_{m}\right]^{*} \\
\rightarrow \mathrm{Mg}^{+}\left(\mathrm{CH}_{3} \mathrm{OH}\right)_{n}+(m-n) \mathrm{CH}_{3} \mathrm{OH}
\end{gathered}
$$

The association products are probably stabilized by evaporation of one methanol molecule or by collision with the carrier gas. For clusters larger than $\mathrm{Mg}^{+}\left(\mathrm{CH}_{3} \mathrm{OH}\right)_{4}$, the cluster ion 


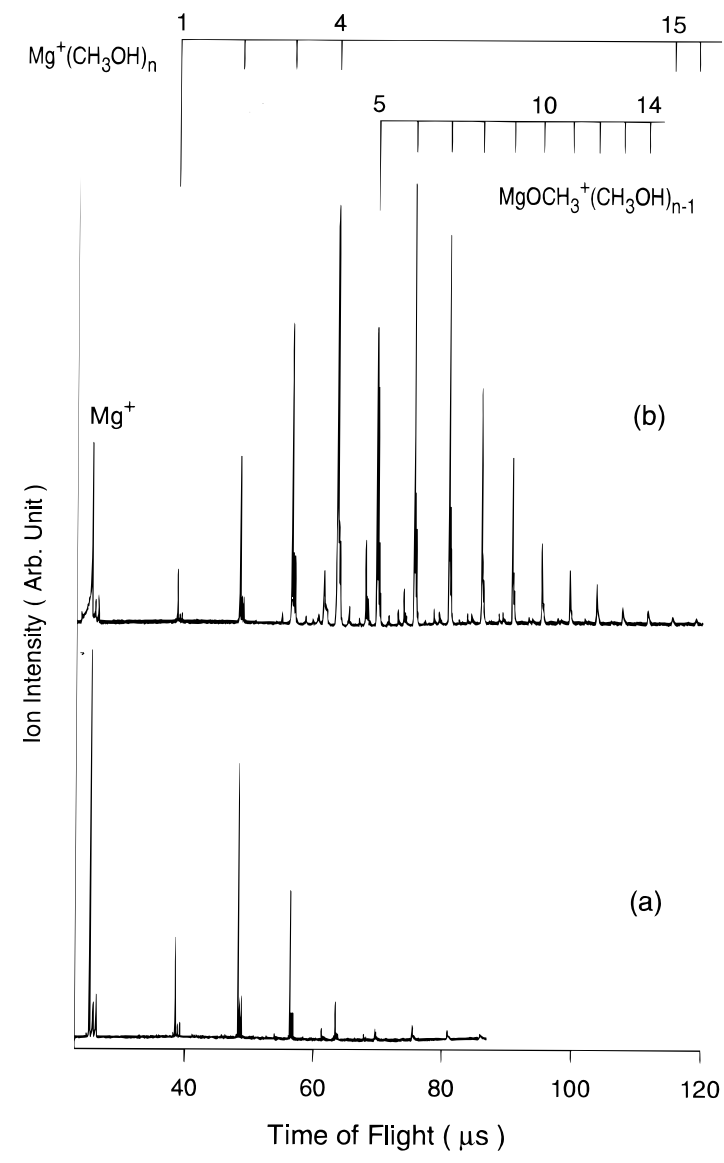

Figure 3. Time-of-flight mass spectra of the product ions for the reaction of $\mathrm{Mg}^{+}$with $\mathrm{CH}_{3} \mathrm{OH}$ clusters. (a) The pulsed deflector voltage is off and the voltage for the MCP detector is $-1320 \mathrm{~V}$. (b) The pulsed deflector voltage is on for reducing the intensities of the predominant smaller clusters. The voltage for the MCP detector is $-1600 \mathrm{~V}$.

intensity decreases rapidly with increasing cluster size. To observe the large cluster ions, a pulsed high-voltage deflector was used to deflect the most abundant small cluster ions so that the detector gain can be increased. By appropriately choosing the pulse delay, pulse length, amplitude of the pulsed high voltage, and the voltage of the MCP detector, we could detect large cluster ions in a relatively broad TOF window.

The mass spectrum of larger cluster ions after reducing the small cluster ion intensities by the pulsed high voltage deflector is shown in Figure 3b. Clusters with up to 20 methanol units can be clearly observed. While it may appear at first glance that the mass peaks could be fitted to the formula $\mathrm{Mg}^{+}\left(\mathrm{CH}_{3}-\right.$ $\mathrm{OH})_{n}$, careful mass analysis of the spectrum reveals that the H-elimination products $\mathrm{MgOCH}_{3}{ }^{+}\left(\mathrm{CH}_{3} \mathrm{OH}\right)_{n-1}$ were produced with a characteristic size distribution. The $\mathrm{Mg}^{+}\left(\mathrm{CH}_{3} \mathrm{OH}\right)_{n}$ cluster ions dominate the products for small cluster ions until $n$ $=5$. At $n=5$, a significant intensity dip in the mass spectrum in Figure 3 marks a sharp switching of the reaction product from $\mathrm{Mg}^{+}\left(\mathrm{CH}_{3} \mathrm{OH}\right)_{5}$ to $\mathrm{MgOCH}_{3}{ }^{+}\left(\mathrm{CH}_{3} \mathrm{OH}\right)_{4}$ through the following reaction:

$$
\mathrm{Mg}^{+}\left(\mathrm{CH}_{3} \mathrm{OH}\right)_{n} \rightarrow \mathrm{MgOCH}_{3}^{+}\left(\mathrm{CH}_{3} \mathrm{OH}\right)_{n-1}+\mathrm{H}, n \geq 5
$$

This product switching can be more clearly seen in Figure 4. For $n=4$, only a single large peak corresponding to $\mathrm{Mg}^{+}\left(\mathrm{CH}_{3}-\right.$ $\mathrm{OH})_{4}$ dominates along with two small peaks due to the isotopes of the $\mathrm{Mg}$. At $n=5$, however, two relatively large peaks appeared, corresponding to $\mathrm{MgOCH}_{3}{ }^{+}\left(\mathrm{CH}_{3} \mathrm{OH}\right)_{4}$ and $\mathrm{Mg}^{+}\left(\mathrm{CH}_{3} \mathrm{OH}\right)_{5}$, respectively. Here the intensity of the former

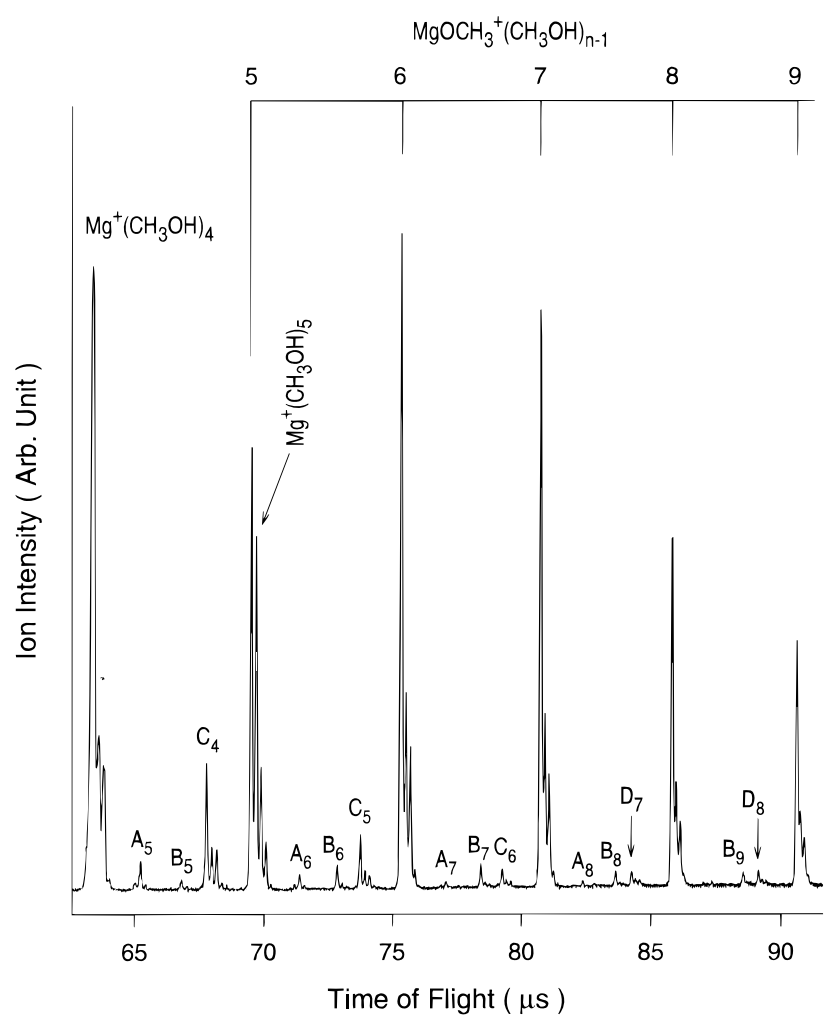

Figure 4. Time-of-flight mass spectrum showing the first product switching region where $\mathrm{Mg}^{+}\left(\mathrm{CH}_{3} \mathrm{OH}\right)_{n}$ change to $\mathrm{MgOCH}_{3}{ }^{+}\left(\mathrm{CH}_{3} \mathrm{OH}\right)_{n-1}$. $\mathrm{A}_{n}: \mathrm{H}^{+}\left(\mathrm{CH}_{3} \mathrm{OH}\right)_{n} ; \mathrm{B}_{n}: \quad \mathrm{MgOH}^{+}\left(\mathrm{CH}_{3} \mathrm{OH}\right)_{n-1} . \mathrm{C}_{n}: \quad \mathrm{Mg}_{2}\left(\mathrm{OCH}_{3}\right)_{2}{ }_{-}$ $\left(\mathrm{CH}_{3} \mathrm{OH}\right)_{n-2}$. $\mathrm{D}_{n}: \mathrm{Mg}_{2}\left(\mathrm{OCH}_{3}\right)_{3}{ }^{+}\left(\mathrm{CH}_{3} \mathrm{OH}\right)_{n-3}$.

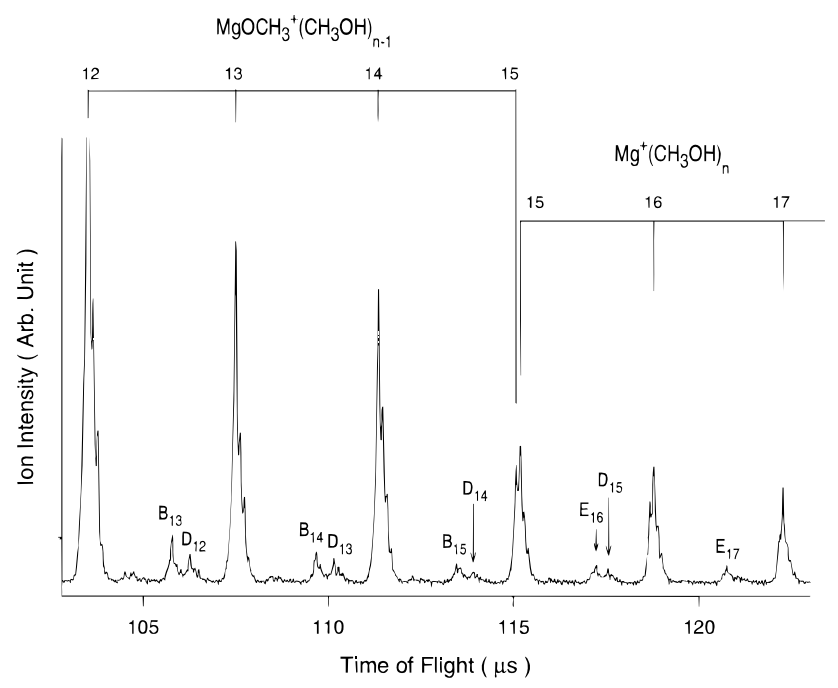

Figure 5. Time-of-flight mass spectrum showing the second product switching region where $\mathrm{MgOCH}_{3}{ }^{+}\left(\mathrm{CH}_{3} \mathrm{OH}\right)_{n-1}$ shift back to $\mathrm{Mg}^{+}\left(\mathrm{CH}_{3}-\right.$ $\mathrm{OH})_{n} . \mathrm{B}_{n}: \mathrm{MgOH}^{+}\left(\mathrm{CH}_{3} \mathrm{OH}\right)_{n-1} . \mathrm{D}_{n}: \mathrm{Mg}_{2}\left(\mathrm{OCH}_{3}\right)_{3}{ }^{+}\left(\mathrm{CH}_{3} \mathrm{OH}\right)_{n-3} . \mathrm{E}_{n}:$ $\mathrm{Mg}^{+} \mathrm{H}_{2} \mathrm{O}\left(\mathrm{CH}_{3} \mathrm{OH}\right)_{n-1}$.

is only slightly larger than that of the latter. However, for $n>$ $5, \mathrm{MgOCH}_{3}{ }^{+}\left(\mathrm{CH}_{3} \mathrm{OH}\right)_{n-1}$ becomes the dominating species with very little $\mathrm{Mg}^{+}\left(\mathrm{CH}_{3} \mathrm{OH}\right)_{n}$ series left. This reaction pattern continues with increasing cluster size until $n=15$, where $\mathrm{Mg}^{+}\left(\mathrm{CH}_{3} \mathrm{OH}\right)_{n}$ become the major species again as seen in Figure 5. This constitutes the second reaction pattern switching for the metal ion-solvent cluster system.

Further analysis of the mass spectra shown in Figures 3-5 revealed that there are some other reaction products with much smaller intensities. The first corresponds to protonated methanol clusters $\mathrm{H}^{+}\left(\mathrm{CH}_{3} \mathrm{OH}\right)_{n}$ (labeled as $\left.\mathrm{A}_{n}\right)$. We suspect that these species are from an electron impact ionization process, during 
which the needed electrons were provided by the laser ablation process. The intensities of this series of cluster ions are rather small and quickly decrease with increasing cluster size. For clusters with $n>9$, the cluster ion cannot be observed.

Another series labeled as $\mathrm{B}_{n}$ starts to emerge for $n \geq 5$ as seen in Figure 4. Interestingly, it corresponds to the $\mathrm{MgOH}^{+}\left(\mathrm{CH}_{3} \mathrm{OH}\right)_{n-1}$. As this series of cluster ions was not observed for small $n$ and starts at a similar cluster size as $\mathrm{MgOCH}_{3}{ }^{+}\left(\mathrm{CH}_{3} \mathrm{OH}\right)_{n-1}$, we attribute this series to the product of the following reaction with $\mathrm{CH}_{3}$ elimination:

$$
\mathrm{Mg}^{+}\left(\mathrm{CH}_{3} \mathrm{OH}\right)_{n} \rightarrow \mathrm{MgOH}^{+}\left(\mathrm{CH}_{3} \mathrm{OH}\right)_{n-1}+\mathrm{CH}_{3}
$$

The intracluster reaction of $\mathrm{Mg}^{+}\left(\mathrm{CH}_{3} \mathrm{OH}\right)_{n}$ appears to have two elimination channels open: $\mathrm{H}$-elimination and $\mathrm{CH}_{3}$ elimination, with the former being the predominating process. The thermodynamic data shows that $\mathrm{CH}_{3}-\mathrm{OH}$ bond dissociation energy is $92 \mathrm{kcal} / \mathrm{mol}$, a value that is smaller than that of the $\mathrm{CH}_{3} \mathrm{O}-\mathrm{H}$ bond $(105 \mathrm{kcal} / \mathrm{mol}){ }^{23}$ The facile elimination of $\mathrm{H}$ is perhaps due to its small size and the isotropic distribution of its s electron, ${ }^{24}$ which makes it kinetically more favorable than the $\mathrm{CH}_{3}$-elimination. The $\mathrm{MgOH}^{+}\left(\mathrm{CH}_{3} \mathrm{OH}\right)_{n-1}$ cluster ion coexists with $\mathrm{MgOCH}_{3}{ }^{+}\left(\mathrm{CH}_{3} \mathrm{OH}\right)_{n-1}$ for $n=5-15$. However, for $n \geq 15$, both cluster ion intensities decrease quickly and switch to cluster ions with one mass number difference. $\mathrm{MgOCH}_{3}{ }^{+}\left(\mathrm{CH}_{3} \mathrm{OH}\right)_{n-1}$ shifts back to $\mathrm{Mg}^{+}\left(\mathrm{CH}_{3} \mathrm{OH}\right)_{n}$ while $\mathrm{MgOH}^{+}\left(\mathrm{CH}_{3} \mathrm{OH}\right)_{n-1}$ shifts to a cluster ion series with a formula $\mathrm{MgH}_{2} \mathrm{O}^{+}\left(\mathrm{CH}_{3} \mathrm{OH}\right)_{\mathrm{n}}$ (labeled as $\left.\mathrm{E}_{n}\right)$.

It is also interesting to note another series $\mathrm{Mg}_{2}\left(\mathrm{OCH}_{3}\right)_{2}{ }^{+}\left(\mathrm{CH}_{3} \mathrm{OH}\right)_{n-2}$ (labeled as $\mathrm{C}_{n}$ in Figure 4), originating from the reaction of magnesium metal dimer cation $\mathrm{Mg}_{2}{ }^{+}$ with the methanol clusters. In this case, two hydrogen atoms have been eliminated and the eliminated product may very well be $\mathrm{H}_{2}$ simply from the energetic arguments. A surprising finding in this series of cluster ions is that they can further dehydrogenate to give $\mathrm{Mg}_{2}\left(\mathrm{OCH}_{3}\right)_{3}{ }^{+}\left(\mathrm{CH}_{3} \mathrm{OH}\right)_{n-3}$ (labeled as $\mathrm{D}_{n}$, see Figures 4 and 5).

2.2. Deuterium Substitution Effects. To investigate the isotope effect for the reactions described above, experiments were performed for $\mathrm{Mg}^{+}$with deuterated methanol samples, namely $\mathrm{CH}_{3} \mathrm{OD}, \mathrm{CD}_{3} \mathrm{OH}$, and $\mathrm{CD}_{3} \mathrm{OD}$. These isotope substitution experiments also serve to confirm our previous mass assignments.

The mass spectra for the reactions of $\mathrm{Mg}^{+}$with $\left(\mathrm{CH}_{3} \mathrm{OH}\right)_{n}$, $\left(\mathrm{CH}_{3} \mathrm{OD}\right)_{n},\left(\mathrm{CD}_{3} \mathrm{OH}\right)_{n}$, and $\left(\mathrm{CD}_{3} \mathrm{OD}\right)_{n}$ are presented in Figures 6 and 7. To facilitate comparison, the $x$-axis in the mass spectra is converted to the number of methanol molecules $n$ in the cluster. Evidently, the mass resolution of the spectra is sufficiently high to resolve one unit of difference in mass for clusters of as large as $16 \mathrm{CD}_{3} \mathrm{OD}$ molecules.

The reaction products for clusters containing 4-7 methanol molecules can be identified in the mass spectra in Figure 6. This region corresponds to the first product switching, where the $\mathrm{Mg}^{+}\left(\mathrm{CH}_{3} \mathrm{OH}\right)_{n}$ cluster ions dehydrogenate to give $\mathrm{MgOMe}^{+}\left(\mathrm{CH}_{3} \mathrm{OH}\right)_{n-1}$. For $\mathrm{CH}_{3} \mathrm{OH}$, this switching occurs at $n=5$ as described above. When the $\mathrm{OH}$ group in $\mathrm{CH}_{3} \mathrm{OH}$ is substituted by the OD group, the switching point is clearly shifted to larger clusters by one methanol unit. For both $\mathrm{CH}_{3} \mathrm{OD}$ and $\mathrm{CD}_{3} \mathrm{OD}$, the association product ions $\mathrm{Mg}^{+}\left(\mathrm{CH}_{3} \mathrm{OH}\right)_{n}$ are still dominant for $n \geq 5$, although small peaks corresponding to $\mathrm{MgOMe}^{+}\left(\mathrm{CH}_{3} \mathrm{OH}\right)_{n-1}$ start to appear on the left sides of the strong peaks for $n=4$ and 5. Only for $n \geq 6$ does the series $\mathrm{MgOMe}^{+}\left(\mathrm{CH}_{3} \mathrm{OH}\right)_{n-1}$ really takes over the series of the association product ions. For $\mathrm{CD}_{3} \mathrm{OH}$, the situation is very similar to that of $\mathrm{CH}_{3} \mathrm{OH}$. The first product switching occurs
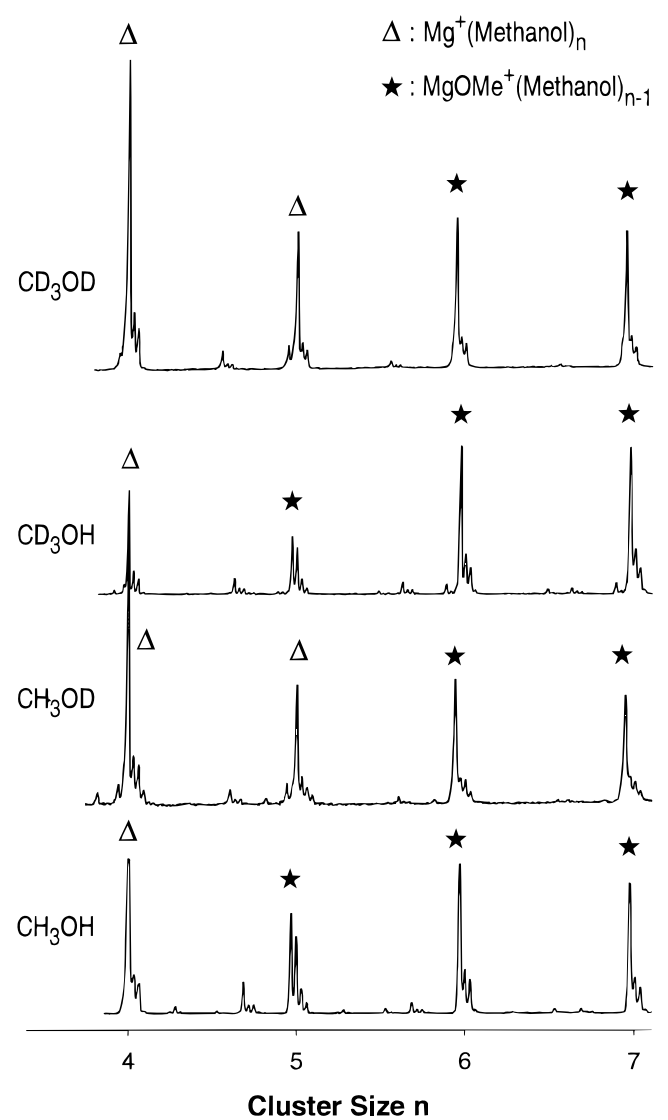

Figure 6. Time-of-flight mass spectra in the first switching region for reactions of $\mathrm{Mg}^{+}$with deuterium-substituted methanol clusters. From top to bottom: $\mathrm{CD}_{3} \mathrm{OD}, \mathrm{CD}_{3} \mathrm{OH}, \mathrm{CH}_{3} \mathrm{OD}$, and $\mathrm{CH}_{3} \mathrm{OH}$.

at $n=5$, where the intensity of $\mathrm{MgOCD}_{3}+\left(\mathrm{CD}_{3} \mathrm{OH}\right)_{4}$ becomes larger than that of $\mathrm{Mg}^{+}\left(\mathrm{CD}_{3} \mathrm{OH}\right)_{5}$. This similarity is not surprising since the dehydrogenation reaction involves only the $\mathrm{O}-\mathrm{H}$ bond cleavage, on which the replacement of $\mathrm{CH}_{3}$ with $\mathrm{CD}_{3}$ has little effect.

Shown in Figure 7 are the mass spectra of the product ions for clusters containing 13-16 methanol molecules. A second product switching from $\mathrm{MgOMe}{ }^{+}\left(\mathrm{CH}_{3} \mathrm{OH}\right)_{n-1}$ back to $\mathrm{Mg}^{+}\left(\mathrm{CH}_{3^{-}}\right.$ $\mathrm{OH})_{n}$ can be clearly seen in Figure 7 . The mass resolution in this high-mass region is slightly lower, but is still high enough to distinguish the difference of one atomic mass unit. Again, the $x$-axis of the mass spectra in Figure 7 is converted to the $\mathrm{Mg}^{+}\left(\mathrm{CH}_{3} \mathrm{OH}\right)_{n}$ cluster size $n$ for the sake of comparison.

For $\mathrm{CH}_{3} \mathrm{OH}$ and $\mathrm{CD}_{3} \mathrm{OH}$, the critical sizes for the second switching are the same (i.e., both are at $n=15$ ). For example, in the intracluster reactions of $\mathrm{Mg}^{+}\left(\mathrm{CD}_{3} \mathrm{OH}\right)_{n}$, the intensities of the product ions $\mathrm{MgOCD}_{3}+\left(\mathrm{CD}_{3} \mathrm{OH}\right)_{n-1}$ at $n=14$ are very strong, and there are almost no $\mathrm{Mg}^{+}\left(\mathrm{CD}_{3} \mathrm{OH}\right)_{14}$ signals. However, at $n=15$, the $\mathrm{H}$-elimination product appears as a shoulder on the left of the stronger $\mathrm{Mg}^{+}\left(\mathrm{CD}_{3} \mathrm{OH}\right)_{15}$ peak. The intensities of $\mathrm{MgOCD}_{3}+\left(\mathrm{CD}_{3} \mathrm{OH}\right)_{n-1}$ ions decrease further with increasing cluster size. In much the same way as seen in the first product switching, it appears that the $\mathrm{CH}_{3} / \mathrm{CD}_{3}$ exchange has no effect on the critical size of the second product switching.

The effect of OH/OD exchange on the second product switching was also examined. In contrast to the situation for the $\mathrm{CH}_{3} / \mathrm{CD}_{3}$ exchange, where there was no observable effect, the OH/OD exchange shifts the second product switching point to smaller clusters by one methanol unit. As can be appreciated in Figure 7 , for both $\mathrm{CH}_{3} \mathrm{OD}$ and $\mathrm{CD}_{3} \mathrm{OD}$, the $\mathrm{MgOMe}^{+}\left(\mathrm{CH}_{3} \mathrm{OH}\right)_{n-1}$ ion intensity is larger than that of $\mathrm{Mg}^{+}\left(\mathrm{CH}_{3} \mathrm{OH}\right)_{n}$ at $n=13$, but their intensities are reversed at $n$ 


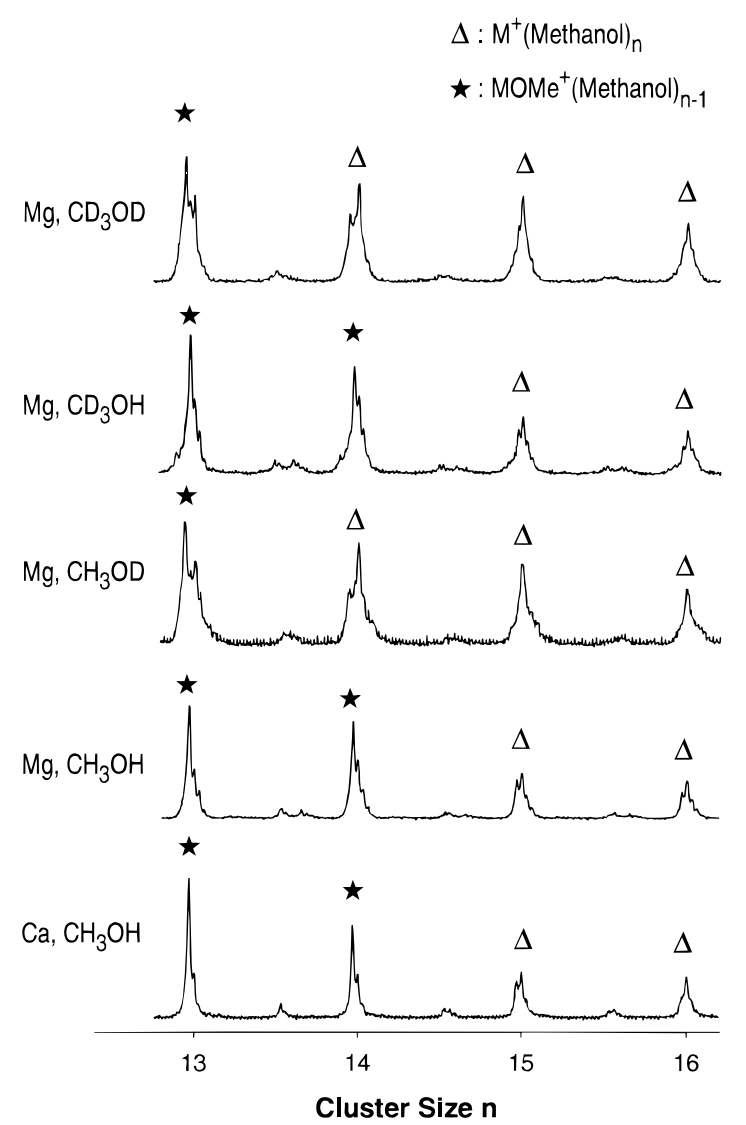

Figure 7. Time-of-flight mass spectra in the second switching region for reactions of $\mathrm{Mg}^{+}$and $\mathrm{Ca}^{+}$with deuterium substituted methanol clusters. From top to bottom: $\mathrm{Mg}^{+}-\mathrm{CD}_{3} \mathrm{OD}, \mathrm{Mg}^{+}-\mathrm{CD}_{3} \mathrm{OH}, \mathrm{Mg}^{+}-$ $\mathrm{CH}_{3} \mathrm{OD}, \mathrm{Mg}^{+}-\mathrm{CH}_{3} \mathrm{OH}$, and $\mathrm{Ca}^{+}-\mathrm{CH}_{3} \mathrm{OH}$.

$=14$. The cluster ions $\mathrm{Mg}^{+}\left(\mathrm{CH}_{3} \mathrm{OH}\right)_{n}$ after $\mathrm{OH} / \mathrm{OD}$ exchange become the dominant species again for $n \geq 14$ instead of $n \geq$ 15 as observed for the cluster reactions without the OH/OD exchange.

As a brief summary, the deuterium substitution at different positions of the methanol molecule has different effects on the critical sizes of both the first and second product switchings. No change in critical size was observed when the hydrogen atoms in the $\mathrm{CH}_{3}$ group were replaced by deuterium atoms. On the other hand, replacing the hydrogen atom in the $\mathrm{OH}$ group with deuterium atom changes the critical sizes of the two product switchings by one methanol unit. $\mathrm{MgOCH}_{3}{ }^{+}\left(\mathrm{CH}_{3} \mathrm{OD}\right)_{n-1}$ and $\mathrm{MgOCD}_{3}{ }^{+}\left(\mathrm{CD}_{3} \mathrm{OD}\right)_{n-1}$ cluster ions fall mainly into a narrowed cluster size window $(6 \leq n \leq 13)$ as compared with $\mathrm{MgOCH}_{3}{ }^{+}\left(\mathrm{CH}_{3} \mathrm{OH}\right)_{n-1}$ and $\mathrm{MgOCD}_{3}+\left(\mathrm{CD}_{3} \mathrm{OH}\right)_{n-1}(5 \leq n \leq$ 14). The product ions $\mathrm{Mg}^{+}\left(\mathrm{CH}_{3} \mathrm{OD}\right)_{n}$ and $\mathrm{Mg}^{+}\left(\mathrm{CD}_{3} \mathrm{OD}\right)_{n}$ are the dominant species in the range for $n \leq 5$ and $n \leq 14$.

2.3. Reactions of $\mathrm{Ca}^{+}, \mathrm{Sr}^{+}$, and $\mathrm{Ba}^{+}$with $\mathrm{CH}_{3} \mathrm{OH}$ Clusters. The reactions of $\mathrm{Ca}^{+}, \mathrm{Sr}^{+}$, and $\mathrm{Ba}^{+}$with methanol molecules show some different features compared with that of $\mathrm{Mg}^{+}$. While $\mathrm{Mg}^{+}$is nonreactive toward the methanol molecule (only the association product ion $\mathrm{Mg}^{+}\left(\mathrm{CH}_{3} \mathrm{OH}\right)$ was formed $), \mathrm{Ca}^{+}, \mathrm{Sr}^{+}$ and $\mathrm{Ba}^{+}$can react with methanol as can be seen in the mass spectra shown in Figure 8. For comparison among different metals, the $x$-axis of the mass spectra is scaled to the cluster size $n$ of $\mathrm{M}^{+}\left(\mathrm{CH}_{3} \mathrm{OH}\right)_{n}(\mathrm{M}=\mathrm{Ca}, \mathrm{Sr}$, and $\mathrm{Ba})$. The mass spectra show that for the reactions of $\mathrm{Ca}^{+}, \mathrm{Sr}^{+}$, and $\mathrm{Ba}^{+}$with one methanol molecule, both $\mathrm{H}$-elimination products $\mathrm{MOCH}_{3}{ }^{+}$and $\mathrm{CH}_{3}$-elimination products $\mathrm{MOH}^{+}$can be formed in addition to the association product $\mathrm{M}^{+}\left(\mathrm{CH}_{3} \mathrm{OH}\right)$. However, these two products were not observed for the reaction of $\mathrm{Mg}^{+}$with the

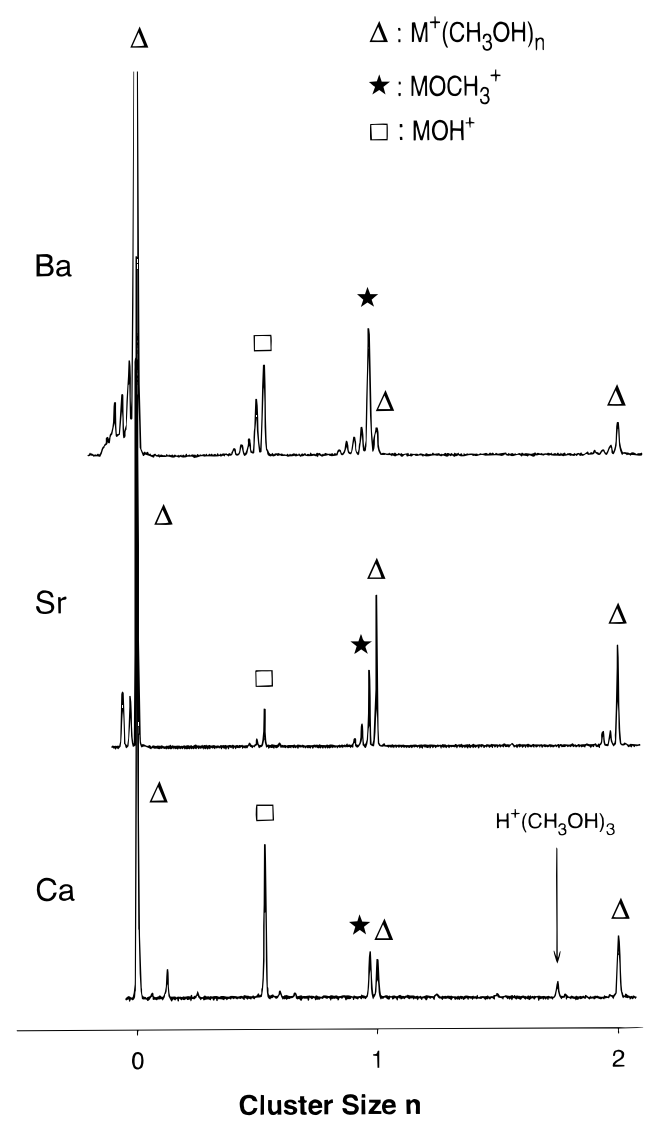

Figure 8. Time-of-flight mass spectra showing the product ions from reactions of $\mathrm{Ca}^{+}, \mathrm{Sr}^{+}$, and $\mathrm{Ba}^{+}$with methanol monomer and dimer.

methanol molecule. This is consistent with a recent result of Gibson et al., who reported the formation of $\mathrm{BaOH}^{+}$and $\mathrm{BaOCH}_{3}{ }^{+}$when using laser ablated $\mathrm{Ba}^{+}$to react with $\mathrm{CH}_{3} \mathrm{OH}$ in gas phase. ${ }^{25}$

The fact that we used metal oxides to generate $\mathrm{Ca}^{+}, \mathrm{Sr}^{+}$, and $\mathrm{Ba}^{+}$and a metal target to generate $\mathrm{Mg}^{+}$for the reaction may result in ambiguity in comparing the results among the four metal ions. One might speculate that the different reactivities of alkaline earth metal ions with the methanol molecule could arise from the different laser-ablating materials we used. To clarify this point, we also tried to use $\mathrm{MgO}$ to generate $\mathrm{Mg}^{+}$and found no difference in product distribution. The differences in reactivity among the four metal ions are most likely due to the different thermodynamic properties.

The $\mathrm{CH}_{3}$ elimination reaction proceeds by breaking the $\mathrm{C}-\mathrm{O}$ bond in $\mathrm{CH}_{3} \mathrm{OH}$ and forming the $\mathrm{M}^{+}-\mathrm{OH}$ bond. Since the $\mathrm{CH}_{3}-\mathrm{OH}$ bond energy is $92 \mathrm{kcal} / \mathrm{mol}^{23}$ and the binding energy of $\mathrm{Mg}^{+}-\mathrm{OH}$ is $76 \mathrm{kcal} / \mathrm{mol},{ }^{26}$ we estimate that the groundstate reaction for $\mathrm{Mg}^{+}$is endothermic by about $16 \mathrm{kcal} / \mathrm{mol}$. For other alkaline earth metal ions, the reactions are exothermic and readily occur. For example, as the binding energy for $\mathrm{Ca}^{+}-$ $\mathrm{OH}$ is $106 \mathrm{kcal} / \mathrm{mol},{ }^{27}$ we find that the reaction leading to the formation of $\mathrm{CaOH}^{+}$and $\mathrm{CH}_{3}$ is exothermic by $14 \mathrm{kcal} / \mathrm{mol}$. The reactions for $\mathrm{Sr}^{+}$and $\mathrm{Ba}^{+}$are expected to be more exothermic from the available data on the binding energies for $\mathrm{Sr}^{+}-\mathrm{OH}$ and $\mathrm{Ba}^{+}-\mathrm{OH} \cdot{ }^{27}$

The $\mathrm{H}$-elimination reaction leads to the breakage of the $\mathrm{O}-\mathrm{H}$ bond in $\mathrm{CH}_{3} \mathrm{OH}$ and this is compensated by the formation of $\mathrm{M}^{+}-\mathrm{OCH}_{3}$ bond. The binding energies of $\mathrm{M}^{+}-\mathrm{OCH}_{3}$ are not available yet. However, considering that $\mathrm{CH}_{3}$ is more polarizable than $\mathrm{H}$ and that this would increase the ligand contribution to the bonding, ${ }^{10}$ we expect that the binding energy for $\mathrm{M}^{+-}$ 
$\mathrm{OCH}_{3}$ should be larger than that of $\mathrm{M}^{+}-\mathrm{OH}$. Thus, although the $\mathrm{CH}_{3} \mathrm{O}-\mathrm{H}$ bond dissociation energy is $105 \mathrm{kcal} / \mathrm{mol},{ }^{23}$ which is $13 \mathrm{kcal} / \mathrm{mol}$ larger than that of $\mathrm{CH}_{3}-\mathrm{OH}$, the large bond dissociation energy of $\mathrm{M}^{+}-\mathrm{OCH}_{3}$ can still make the $\mathrm{H}$ elimination reaction exothermic for $\mathrm{Ca}^{+}, \mathrm{Sr}^{+}$, and $\mathrm{Ba}^{+}$. Especially for $\mathrm{Ba}^{+}$, very few association products $\mathrm{Ba}^{+}\left(\mathrm{CH}_{3} \mathrm{OH}\right)$ are formed compared to $\mathrm{BaOH}^{+}$and $\mathrm{BaOCH}_{3}{ }^{+}$, possibly due to the larger binding energies for $\mathrm{Ba}^{+}-\mathrm{OH}$ and $\mathrm{Ba}^{+}-\mathrm{OCH}_{3}$. Again, for $\mathrm{Mg}^{+}$, the $\mathrm{H}$-elimination reaction is still endothermic.

The results presented above also indicate that the reaction between the laser-ablated alkaline earth metal ion and methanol molecule occurs on the ground-state surface. The ${ }^{2} \mathrm{P}$ excited state of $\mathrm{Mg}^{+}$is known to be $102.2 \mathrm{kcal} / \mathrm{mol}$ above the ground state ${ }^{2} \mathrm{~S} .{ }^{28}$ Such a high internal energy is far more than enough to induce the $\mathrm{CH}_{3}$-elimination and $\mathrm{H}$-elimination reactions with $\mathrm{CH}_{3} \mathrm{OH}$, leading to the formation of $\mathrm{MgOH}^{+}$and $\mathrm{MgOCH}_{3}{ }^{+}$. However, the fact that these two products were not observed implies that the excited-state metal ion species did not participate in the reaction.

Another important point in Figure 8 is that the reactions of the alkaline earth metal ions with methanol dimer give only the association products. This is surprising especially for $\mathrm{Ca}^{+}$, $\mathrm{Sr}^{+}$, and $\mathrm{Ba}^{+}$since, based on thermodynamic data, the $\mathrm{CH}_{3}-$ elimination and $\mathrm{H}$-elimination reactions should be more exothermic for the methanol dimer than for the monomer. It is likely that, for the methanol dimer reaction, the collision complex can be stabilized by evaporation of the constituent methanol molecules, yielding the association product ion without reaction. Another possibility is that the lifetime of the collision complex is so long that it is eventually stabilized by the collision, most probably with the carrier gas, again forming the association product ion. This continues to be the case until the cluster size reaches $\sim 5$, where the first product switching takes place.

The mass spectra of the product ions from $\mathrm{Ca}^{+}\left(\mathrm{CH}_{3} \mathrm{OH}\right)_{n}$, $\mathrm{Sr}^{+}\left(\mathrm{CH}_{3} \mathrm{OH}\right)_{n}$, and $\mathrm{Ba}^{+}\left(\mathrm{CH}_{3} \mathrm{OH}\right)_{n}$ and $\mathrm{Mg}^{+}\left(\mathrm{CH}_{3} \mathrm{OH}\right)_{n}$ in the cluster size range from $n=3-7$ are compared in Figure 9. In general, in this size range, the first product switching takes place for all the four alkaline earth metal ions although the exact cluster size for product switching may be somewhat different. As we have shown above, $\mathrm{Mg}^{+}\left(\mathrm{CH}_{3} \mathrm{OH}\right)_{n}$ starts to change to $\mathrm{MgOCH}_{3}{ }^{+}\left(\mathrm{CH}_{3} \mathrm{OH}\right)_{n-1}$ at $n=5$. For $\mathrm{Ca}^{+}$, this critical size changes to $n=4$. As can be seen from the spectra, for $n=3$, the $\mathrm{Ca}^{+}\left(\mathrm{CH}_{3} \mathrm{OH}\right)_{3}$ ion still dominates, although a small peak corresponding to $\mathrm{CaOCH}_{3}{ }^{+}\left(\mathrm{CH}_{3} \mathrm{OH}\right)_{2}$ already appears on the left of the strong peak. Right at $n=4$, their intensities are reversed. This reaction product series continues for even larger clusters up to the second product switching region (see Figure 7) at $n=15$, where $\mathrm{CaOCH}_{3}{ }^{+}\left(\mathrm{CH}_{3} \mathrm{OH}\right)_{n-1}$ shifts back to $\mathrm{Ca}^{+}\left(\mathrm{CH}_{3} \mathrm{OH}\right)_{n}$. This critical size for second product switching is the same as that of $\mathrm{Mg}^{+}$.

Similarly, the first product switching for the reactions of $\mathrm{Sr}^{+}$ and $\mathrm{Ba}^{+}$takes place at $n=5$ and $n=6$, respectively, as can be seen from the mass spectra in Figure 9. Although the mass resolution has deteriorated to a certain extent for larger clusters, careful analysis of the mass spectra reveals that the critical size of the second product switching for the reactions of $\mathrm{Sr}^{+}$is 15 . For the reactions of $\mathrm{Ba}^{+}$, at least for $n \leq 12$, $\mathrm{BaOCH}_{3}{ }^{+}\left(\mathrm{CH}_{3} \mathrm{OH}\right)_{n-1}$ are still the dominant cluster ions. The small signal intensity prevents further analysis for even larger clusters of $\mathrm{Ba}^{+}\left(\mathrm{CH}_{3} \mathrm{OH}\right)_{n}$ with respect to the second product switching.

In general, the reactions of $\mathrm{Ca}^{+}, \mathrm{Sr}^{+}$and $\mathrm{Ba}^{+}$with methanol clusters $\left(\mathrm{CH}_{3} \mathrm{OH}\right)_{n}(n>1)$ exhibit a characteristic product

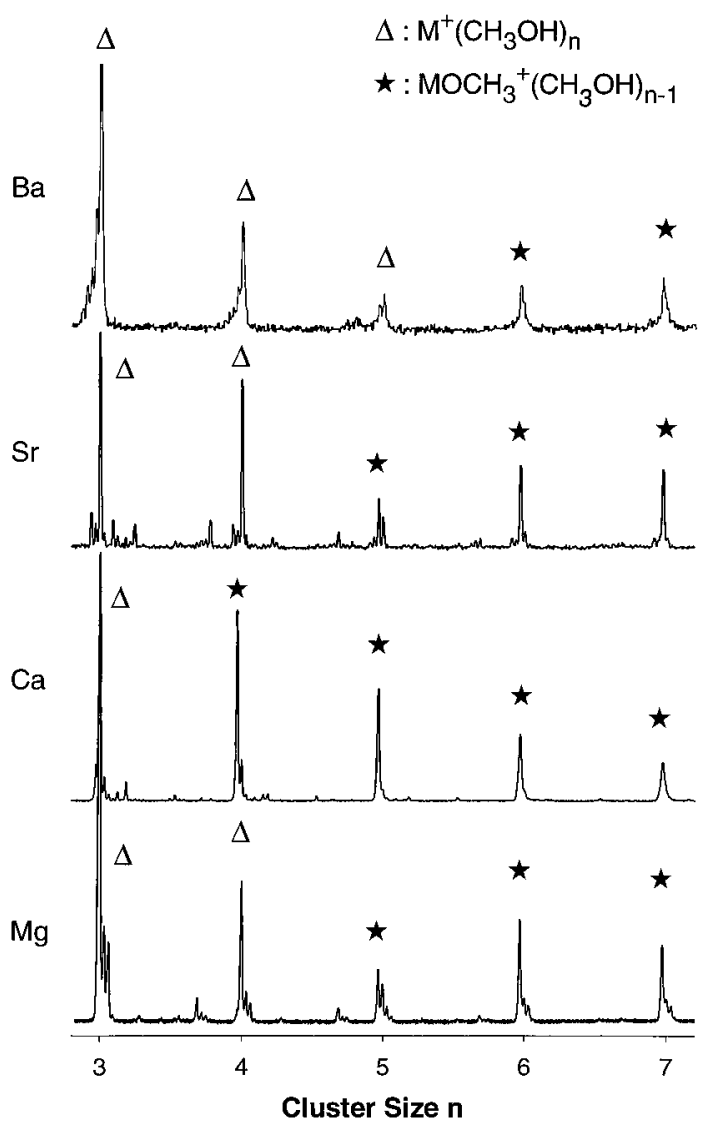

Figure 9. Time-of-flight mass spectra showing the first product switching region for the reactions of alkaline earth metal ions with $\mathrm{CH}_{3} \mathrm{OH}$ clusters. From top to bottom: $\mathrm{Ba}^{+}, \mathrm{Sr}^{+}, \mathrm{Ca}^{+}$, and $\mathrm{Mg}^{+}$.

TABLE 1: Product Distributions for Reactions of Alkaline Earth Metal Ions with Methanol Clusters

\begin{tabular}{|c|c|c|c|}
\hline \multicolumn{2}{|c|}{ reactants } & \multirow{2}{*}{\multicolumn{2}{|c|}{ products }} \\
\hline \multirow{2}{*}{$\begin{array}{c}\text { metal ion } \\
\left(\mathrm{M}^{+}\right)\end{array}$} & \multirow[b]{2}{*}{ methanol } & & \\
\hline & & $\mathrm{M}^{+}\left(\mathrm{CH}_{3} \mathrm{OH}\right)_{n}$ & $\mathrm{MOMe}^{+}\left(\mathrm{CH}_{3} \mathrm{OH}\right)_{n-1}$ \\
\hline \multirow[t]{4}{*}{$\mathrm{Mg}^{+}$} & $\mathrm{CH}_{3} \mathrm{OH}$ & $n \leq 4$ and $n \geq 15$ & $5 \leq n \leq 14$ \\
\hline & $\mathrm{CH}_{3} \mathrm{OD}$ & $n \leq 5$ and $n \geq 14$ & $6 \leq n \leq 13$ \\
\hline & $\mathrm{CD}_{3} \mathrm{OH}$ & $n \leq 4$ and $n \geq 15$ & $5 \leq n \leq 14$ \\
\hline & $\mathrm{CD}_{3} \mathrm{OD}$ & $n \leq 5$ and $n \geq 14$ & $6 \leq n \leq 13$ \\
\hline $\mathrm{Ca}^{+}$ & $\mathrm{CH}_{3} \mathrm{OH}$ & $n \leq 3$ and $n \geq 15$ & $\mathrm{n}=1$ and $4 \leq n \leq 14$ \\
\hline $\mathrm{Sr}^{+}$ & $\mathrm{CH}_{3} \mathrm{OH}$ & $n \leq 4$ and $n \geq 15$ & $\mathrm{n}=1$ and $5 \leq n \leq 14$ \\
\hline $\mathrm{Ba}^{+}$ & $\mathrm{CH}_{3} \mathrm{OH}$ & $n \leq 5 *$ & $n=1$ and $6 \leq n \leq 12^{a}$ \\
\hline
\end{tabular}

${ }^{a}$ Signals are too weak for $n \geq 12$.

distribution similar to that of $\mathrm{Mg}^{+}$in terms of the first and second product switchings. The overall results are presented in Table 1.

V. Computational Results. We performed ab initio calculations on singly charged metal ion-solvent clusters $\mathrm{Mg}^{+}\left(\mathrm{CH}_{3^{-}}\right.$ $\mathrm{OH})_{n}$ and their corresponding $\mathrm{H}$-elimination products $\mathrm{MgOCH}_{3}{ }^{+}\left(\mathrm{CH}_{3} \mathrm{OH}\right)_{n-1}$. The size of the cluster ions in the present study is limited to $n=5$ by the available computation capability. Methanol is a quite large subunit compared with water, and thus the $a b$ initio calculations become very difficult for clusters containing a large number of methanol molecules. Even for a medium-sized cluster ion, many possible isomers may exist originating from the different orientations of the neighboring subunits. We do not intend to perform a comprehensive theoretical study to locate all the possible isomers at high levels. Instead, it is sufficient for our purpose to get a qualitative picture of the gross geometries and relative thermodynamic stability of the two species. 
TABLE 2: Calculated Total Energies of Different Structures for $\mathrm{Mg}^{+}\left(\mathrm{CH}_{3} \mathrm{OH}\right)_{n}(n \leq 5)$ at the $\mathrm{SCF} / 6-31 \mathrm{G}^{*}$ Level as Well as the Relative Energies for Different Isomers ${ }^{a}$

\begin{tabular}{lcccc}
\hline \multicolumn{1}{c}{ species } & structure & $\begin{array}{c}\text { energies } \\
\text { (hartree) }\end{array}$ & $\begin{array}{c}\text { relative } \\
\text { energies } \\
(\mathrm{kJ} / \mathrm{mol})\end{array}$ & $\begin{array}{c}\mathrm{ZPE} \\
(\text { Hartree })\end{array}$ \\
\hline $\mathrm{Mg}^{+}$ & & -199.352158045 & & 0 \\
$\mathrm{CH}_{3} \mathrm{OH}$ & & -115.034237279 & & 0.055307 \\
$\mathrm{Mg}^{+}\left(\mathrm{CH}_{3} \mathrm{OH}\right)$ & $\mathbf{1}$ & -314.448662919 & & 0.057197 \\
$\mathrm{Mg}^{+}\left(\mathrm{CH}_{3} \mathrm{OH}\right)_{2}$ & $\mathbf{2 a}$ & -429.532100589 & 0 & 0.115055 \\
& $\mathbf{2 b}$ & -429.532022320 & 0.21 & \\
$\mathrm{Mg}^{+}\left(\mathrm{CH}_{3} \mathrm{OH}\right)_{3}$ & $\mathbf{3 a}$ & -544.603226558 & 0 & 0.172370 \\
& $\mathbf{3 b}$ & -544.600618244 & 6.87 & \\
$\mathrm{Mg}^{+}\left(\mathrm{CH}_{3} \mathrm{OH}\right)_{4}$ & $\mathbf{4 a}$ & -659.668910660 & 0 & 0.231335 \\
& $\mathbf{4 b}$ & -659.664827986 & 10.70 & \\
& $\mathbf{4 c}$ & -659.662442892 & 17.01 & \\
$\mathrm{Mg}^{+}\left(\mathrm{CH}_{3} \mathrm{OH}\right)_{5}$ & $\mathbf{5}$ & -774.728233616 & & 0.290120
\end{tabular}

${ }^{a} \mathrm{ZPE}$ represents the zero-point energy corrections to the total energies for the most stable isomers.

1

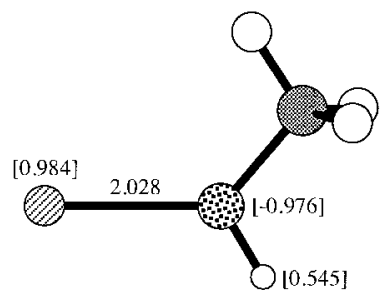

$\mathrm{C}_{\mathrm{s}}$

$2 \mathbf{a}$

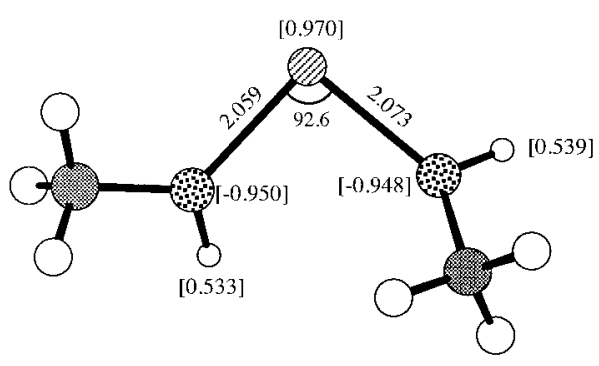

$2 \mathbf{b}$

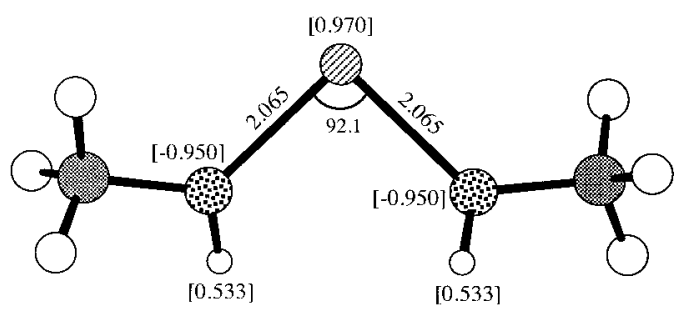

Figure 10. Optimized structures of $\mathrm{Mg}^{+}\left(\mathrm{CH}_{3} \mathrm{OH}\right)(\mathbf{1})$ and $\mathrm{Mg}^{+}\left(\mathrm{CH}_{3}-\right.$ $\mathrm{OH})_{2}(\mathbf{2 a}, \mathbf{2 b})$ at the SCF/6-31G* level. Angles are in degrees and distances are in angstroms. The values in square brackets indicate the natural charge for the corresponding atoms.

1. Structures of $\mathrm{Mg}^{+}\left(\mathrm{CH}_{3} \mathrm{OH}\right)_{n}(\mathbf{1} \leq \boldsymbol{n} \leq \mathbf{5})$. The optimized geometries of $\mathrm{Mg}^{+}\left(\mathrm{CH}_{3} \mathrm{OH}\right)_{n}(1 \leq n \leq 5)$ at the $\mathrm{SCF} /$ 6-31G* level are presented in Figures 10-13. Table 2 summarizes the calculated total energies as well as the relative energies for the structures of $\mathrm{Mg}^{+}\left(\mathrm{CH}_{3} \mathrm{OH}\right)_{n}(n=1-5)$. For the most stable isomers, harmonic vibration frequencies are calculated and the contributions from the zero-point vibration energy are obtained. The calculated zero-point energy corrections are also listed in Table 2.

In structure 1 for $\left(\mathrm{Mg}^{+}\left(\mathrm{CH}_{3} \mathrm{OH}\right)\right.$ shown in Figure $10, \mathrm{Mg}^{+}$ is bonded to the oxygen atom of the methanol molecule and the complex has a $C_{s}$ symmetry. The structure of methanol changes little in the complex from the free methanol molecule, which is consistent with the electrostatic nature of the bond between $\mathrm{Mg}^{+}$and methanol. As $\mathrm{Mg}^{+}$has a 3s electron, it is expected to undergo sp hybridization to reduce the metal-ligand repulsion by polarizing the $3 \mathrm{~s}$ electron density away from the methanol molecule. This results in a high electron density located at the other side of $\mathrm{Mg}$, analogous to the situations for other single s-electron systems (e.g., $\operatorname{Mg}^{+}\left(\mathrm{H}_{2} \mathrm{O}\right)^{19}$ and $\left.\mathrm{Na}\left(\mathrm{H}_{2} \mathrm{O}\right)\right) .{ }^{29,30}$

For $\mathrm{Mg}^{+}\left(\mathrm{CH}_{3} \mathrm{OH}\right)_{2}$, two isomers were studied, which result from the different orientations of the two $\mathrm{OH}$ groups in the two methanol molecules. For both structures, the two methanol molecules were found to be located on the same side of $\mathrm{Mg}^{+}$ as there is a high electron density on the other side of $\mathrm{Mg}^{+}$. The interaction with solvent molecules results in a large polarization of the $3 \mathrm{~s}$ electron density away from the ligands. As shown in Figure 10, for structure 2a, the hydrogen atom in one of the $\mathrm{OH}$ groups points in the opposite direction from the hydrogen atom of the $\mathrm{OH}$ group in another methanol molecule. In structure $\mathbf{2 b}$, the two $\mathrm{OH}$ groups in the two methanol molecules are close to each other, and the steric effect makes the two hydrogen atoms point away from the plane containing the $\mathrm{Mg}^{+}$and the two oxygen atoms. This is similar to the situation in $\mathrm{Mg}^{+}\left(\mathrm{H}_{2} \mathrm{O}\right)_{2}$, where the two water molecules are staggered. ${ }^{5}$ Despite the large steric hindrance expected for structure $\mathbf{2 b}$, the two structures were found to be very close in energy. The structure $\mathbf{2 b}$ is found to be only $0.21 \mathrm{~kJ} / \mathrm{mol}$ less stable than structure 2a. And the $\mathrm{O}-\mathrm{Mg}-\mathrm{O}$ angles in the two structures are also very close; both are around $92^{\circ}$, which is close to that in $\mathrm{Mg}^{+}\left(\mathrm{H}_{2} \mathrm{O}\right)_{2} .{ }^{5}$

Bauchlicher et al. used a larger basis set TZ2P to calculate the structures of $\mathrm{Mg}^{+}\left(\mathrm{CH}_{3} \mathrm{OH}\right)_{n}$ for $n=1$ and 2. ${ }^{10,11}$ Basically, the structures they found are very similar to what we obtained at the $\mathrm{SCF} / 6-31 \mathrm{G}^{*}$ level. There is only a slight difference in the $\mathrm{Mg}-\mathrm{O}$ distances and the $\mathrm{O}-\mathrm{Mg}-\mathrm{O}$ angle. For example, we found the $\mathrm{Mg}-\mathrm{O}$ distance in $\mathrm{Mg}^{+}\left(\mathrm{CH}_{3} \mathrm{OH}\right)$ to be $2.028 \AA$, and the calculation by Bauchlicher et al. gave a value of 2.01 $\AA .{ }^{10}$ The difference in the $\mathrm{O}-\mathrm{Mg}-\mathrm{O}$ angle is found to be even smaller.

For $\mathrm{Mg}^{+}\left(\mathrm{CH}_{3} \mathrm{OH}\right)_{3}$, two structures were investigated as shown in Figure 11. In structure 3a, all the three oxygen atoms in the methanol molecules are directly bonded to $\mathrm{Mg}^{+}$. Whereas, in structure $\mathbf{3 b}$, two methanol molecules are directly bonded to $\mathrm{Mg}^{+}$, forming the first solvation shell, and the third methanol is bonded to the two methanol molecules in the first shell through two hydrogen bonds. Essentially, the three methanol molecules form a six-membered ring with all the six atoms in the ring within the same plane. Our calculation at the SCF/6$31 \mathrm{G}^{*}$ level shows that structure 3a is more stable than structure $\mathbf{3 b}$, although the energy difference between these two isomers is not significant. The relative energy difference is calculated to be $6.87 \mathrm{~kJ} / \mathrm{mol}$. This is in contrast to that of the $\mathrm{Mg}^{+}-$ water cluster system where the energy difference between the two corresponding isomers of $\mathrm{Mg}^{+}\left(\mathrm{H}_{2} \mathrm{O}\right)_{3}$ cluster was calculated to be $14.4 \mathrm{~kJ} / \mathrm{mol}$ at the SCF/6-31G level. ${ }^{5}$ In all probability, the larger size of methanol molecules has some effect on the relative stability between structures $\mathbf{3 a}, \mathbf{b}$. The larger ligandligand repulsions could make structure 3a less favorable as opposed to $\mathrm{Mg}^{+}\left(\mathrm{H}_{2} \mathrm{O}\right)_{3}$ with a similar structure. However, the most stable isomer for $\mathrm{Mg}^{+}\left(\mathrm{CH}_{3} \mathrm{OH}\right)_{3}$ is still the one with three methanol molecules directly bonded to $\mathrm{Mg}^{+}$to form the first solvation shell.

Three isomers, whose structures are shown in Figure 12, were investigated for $\mathrm{Mg}^{+}\left(\mathrm{CH}_{3} \mathrm{OH}\right)_{4}$. Similar to the situation of the 
$3 a$

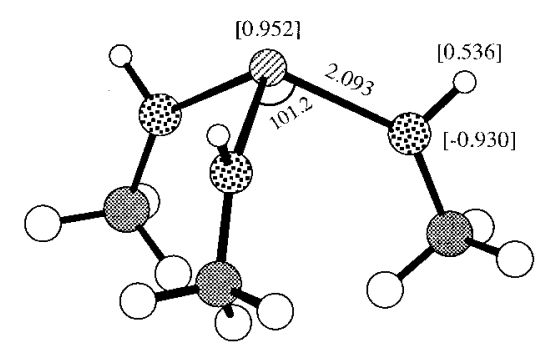

$\mathrm{C}_{3 \mathrm{v}}$

4a

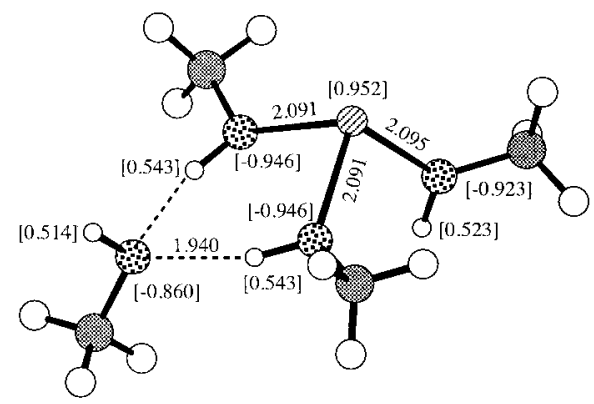

$\mathbf{4 b}$

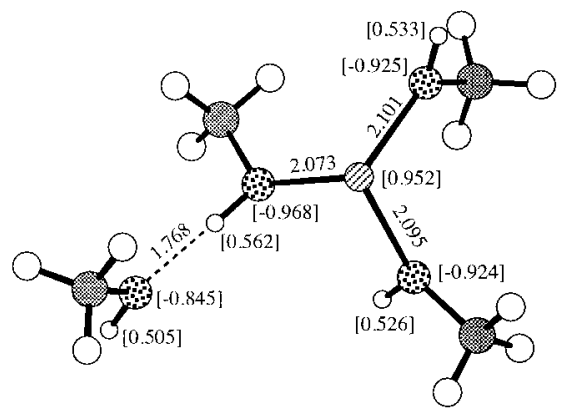

$\mathrm{C}_{\mathrm{s}}$

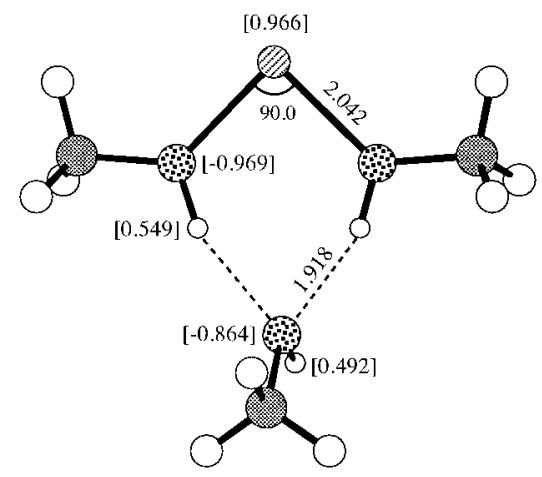

Figure 11. Optimized structures of $\mathrm{Mg}^{+}\left(\mathrm{CH}_{3} \mathrm{OH}\right)_{3}(\mathbf{3 a}, \mathbf{3 b})$ at the $\mathrm{SCF} /$ 6-31G* level. Angles are in degrees and distances are in angstroms. The values in square brackets indicate the natural charge for the corresponding atoms.

smaller clusters, due to the high electron density located on one side of $\mathrm{Mg}^{+}$, all the solvent methanol molecules in the clusters prefer to be located on the other side of $\mathrm{Mg}^{+}$. Structures $\mathbf{4 a}, \mathbf{b}$ both have three methanol molecules in the first solvation shell, and the fourth methanol molecule starts to fill the second solvation shell. However, there are some differences between structures $\mathbf{4 a}, \mathbf{b}$. In structure $\mathbf{4 a}$, the fourth methanol molecule is bonded to two methanol molecules in the first shell through two hydrogen bonds. They form a six-membered ring. For structure $\mathbf{4 b}$, the fourth methanol molecule is bonded to only one methanol molecule in the first shell through one hydrogen bond. The six-membered ring structure in structure $\mathbf{4 a}$ is very similar to that in isomer $\mathbf{3 b}$ for $\mathrm{Mg}^{+}\left(\mathrm{CH}_{3} \mathrm{OH}\right)_{3}$. With such a six-membered ring structure containing two hydrogen bonds, the isomer $\mathbf{4 a}$ is expected to be more stable than the isomer $\mathbf{4 b}$ with only one hydrogen bond. Our calculation at the SCF/6$31 \mathrm{G}^{*}$ level shows that structure $\mathbf{4 a}$ is indeed more stable than structure $\mathbf{4 b}$ with an energy difference of $10.73 \mathrm{~kJ} / \mathrm{mol}$. But the hydrogen-bond length in structure $\mathbf{4 b}(1.768 \AA)$ is much smaller than that in structure $4 \mathbf{a}(1.940 \AA)$. Thus the number of hydrogen bonds is the major factor in determining the relative stability of the isomers. Presumably, the longer hydrogen bonds in structure 4a result from the large ligand-ligand repulsion of the two methanol molecules in the first shell, both of which are bonded to the fourth methanol molecule. Structure 4c corresponds to a structure with all the four methanol molecules directly bonded to $\mathrm{Mg}^{+}$, forming the first solvation shell. This structure is found to be $17.01 \mathrm{~kJ} / \mathrm{mol}$ higher in energy than structure $\mathbf{4 a}$, obviously due to its larger ligand-ligand repulsions among the methanol molecules in the first solvation shell. Thus our calculation shows that the first solvation shell of $\mathrm{Mg}^{+}\left(\mathrm{CH}_{3^{-}}\right.$ $\mathrm{OH})_{n}$ is completed with three methanol molecules, and the fourth methanol molecule will start to fill the second solvation shell.

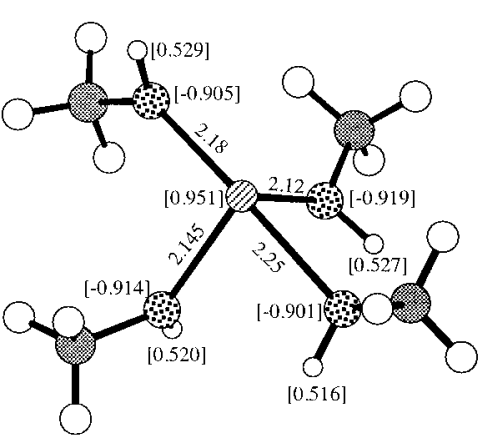

Figure 12. Optimized structures of $\mathrm{Mg}^{+}\left(\mathrm{CH}_{3} \mathrm{OH}\right)_{4}(\mathbf{4 a}, \mathbf{4 b}, \mathbf{4 c})$ at the $\mathrm{SCF} / 6-31 \mathrm{G}^{*}$ level. Distances are in angstroms. The values in square brackets indicate the natural charge for the corresponding atoms.

The methanol molecules in the second shell are connected to the methanol molecules in the first shell through hydrogen bonds with their neighboring $\mathrm{OH}$ groups. Again, this situation is quite similar to that of $\mathrm{Mg}^{+}\left(\mathrm{H}_{2} \mathrm{O}\right)_{n}$ in which it was found that the most stable isomers also have three solvent molecules in the first solvation shell and the addtion of more solvent molecules will start the filling of the second shell.

It is interesting to examine more closely the effect of secondshell formation on the solvent molecules in the first shell. The three methanol molecules in the first shell, which are all directly bonded to $\mathrm{Mg}^{+}$in structure $\mathbf{4 a}$, can be divided into two types. The first type refers to the two methanol molecules, which are both connected with the methanol molecule in the second shell through hydrogen bonds. The second type then embodies the only methanol molecule, which does not bond directly with the methanol molecule in the second shell. From our calculation, it was found that the $\mathrm{Mg}-\mathrm{O}$ bond distance for the first type of methanol molecules $(2.091 \AA)$ is slightly smaller than that for the second type $(2.095 \AA)$. This indicates that the interactions of the methanol molecules in the first shell with the methanol molecules in the second shell result in small geometry change of the methanol molecules of the first shell. The second obvious change is the natural charge of the oxygen atoms and hydrogen atoms in the $\mathrm{OH}$ groups of methanol molecules. The charge of oxygen atoms in the first type of methanol molecules is -0.946 , which is more negative than that in the second type methanol molecule which is -0.923 . The charge of hydrogen 


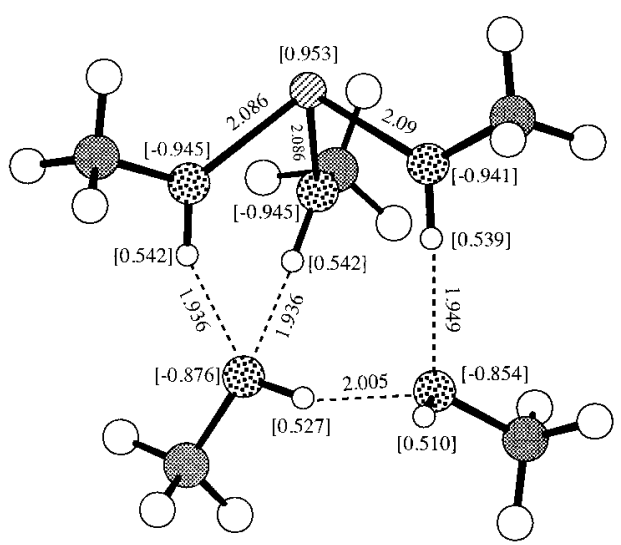

Figure 13. Optimized structures of $\mathrm{Mg}^{+}\left(\mathrm{CH}_{3} \mathrm{OH}\right)_{5}(\mathbf{5})$ at the $\mathrm{SCF} / 6$ $31 \mathrm{G}^{*}$ level. Angles are in degrees and distances are in angstroms. The values in square brackets indicate the natural charge for the corresponding atoms.

atoms in the $\mathrm{OH}$ groups of the first type of methanol molecules is found to be 0.543 , which is more positive than that in the second type of methanol molecule by 0.02 . In other words, the $\mathrm{OH}$ groups are more polarized by the hydrogen bonds with the methanol molecule in the second shell. This phenomenon was observed for all $\mathrm{Mg}^{+}\left(\mathrm{CH}_{3} \mathrm{OH}\right)_{n}$ cluster ions having the second solvation shell. For example, in structure $\mathbf{4 b}$, the charges of $\mathrm{O}$ and $\mathrm{H}$ atoms in the $\mathrm{OH}$ group, which is hydrogen bonded with the methanol in the second shell, are -0.968 and 0.562 , respectively. This results from the strong hydrogen bond with a bond length of only $1.768 \AA$, which is much smaller than that in structure 4a. The bond length of $\mathrm{Mg}-\mathrm{O}(2.073 \AA)$ connected to the first type of methanol molecule is also significantly shorter than those of the other two $\mathrm{Mg}-\mathrm{O}$ bonds ( 2.10 ̊).

For $\mathrm{Mg}^{+}\left(\mathrm{CH}_{3} \mathrm{OH}\right)_{5}$, the largest cluster we investigated, the fifth methanol molecule is expected to be in the second shell as well and bonded to the methanol molecules in the first shell via hydrogen bonds. Figure 13 shows the optimized structure of $\mathrm{Mg}^{+}\left(\mathrm{CH}_{3} \mathrm{OH}\right)_{5}$. There are three methanol molecules in the first shell, which are all directly bonded to $\mathrm{Mg}^{+}$. The fourth methanol molecule is in the second shell and is bonded to two methanol molecules in the first shell through two hydrogen bonds similar in a way to that for the isomer $4 \mathbf{a}$ of $\mathrm{Mg}^{+}\left(\mathrm{CH}_{3}-\right.$ $\mathrm{OH})_{4}$. They form a six-membered ring. The fifth methanol molecule is bonded to two methanol molecules; one is from the first shell, which is not hydrogen bonded to the fourth methanol molecule, and the other is from the second shell. This forms an eight-membered ring, which deforms the planarity of the six-membered ring. Such a stable structure can be considered as being derived from structure 4a. One would wonder if certain stable structures could also be derived from the isomers $\mathbf{4 b}, \mathbf{c}$. The isomers derived from $\mathbf{4 b}$ can have two structures. In the first structure, the fifth methanol molecule is bonded to the two idle methanol molecules in the first shell and further bonded to the fourth methanol molecule through hydrogen bonds. This will form two types of rings, a structure which is essentially the same as structure 5 in Figure 13. The second structure requires the fifth methanol molecule to be bonded to the fourth methanol molecule and one idle methanol molecule in the first shell. This can only form one ring and is not expected to be as stable as isomer 5. Similarly, the structure derived from $\mathbf{4 c}$ can also form only one ring, and the large ligand-ligand repulsions among the four methanol molecules in the first shell make it even more unstable. We therefore believe that the structure 5 corresponds to the most stable isomer for $\mathrm{Mg}^{+}\left(\mathrm{CH}_{3}-\right.$
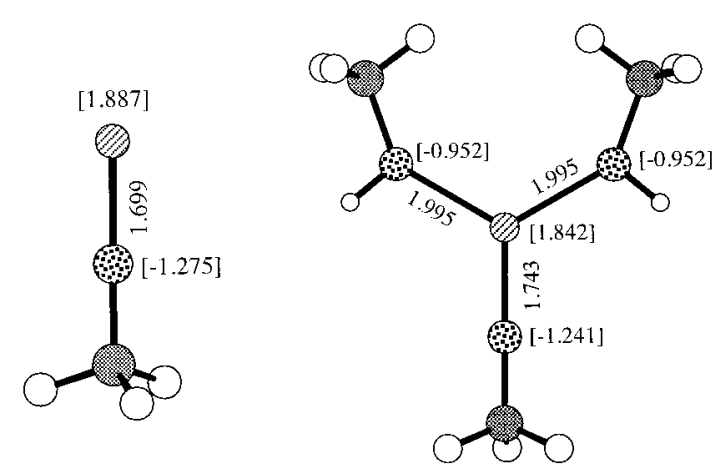

I
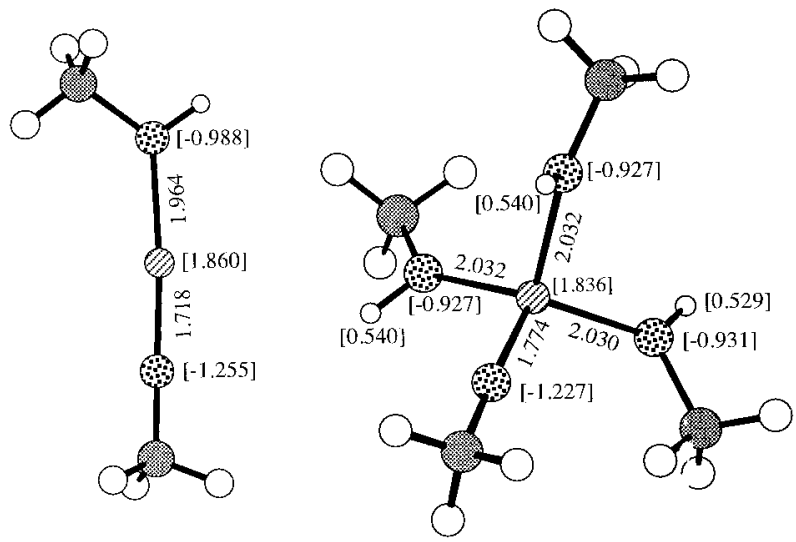

II

VI

Figure 14. Optimized structures of $\mathrm{MgOCH}_{3}{ }^{+}(\mathbf{I}), \mathrm{MgOCH}_{3}{ }^{+}\left(\mathrm{CH}_{3-}\right.$ OH) (II), $\mathrm{MgOCH}_{3}{ }^{+}\left(\mathrm{CH}_{3} \mathrm{OH}\right)_{3}$ (III), and $\mathrm{MgOCH}_{3}{ }^{+}\left(\mathrm{CH}_{3} \mathrm{OH}\right)_{4}$ (IV) at the SCF/6-31G* level. Distances are in angstroms. The values in square brackets indicate the natural charge for the corresponding atoms.

$\mathrm{OH})_{5}$. Interestingly, previous studies by other researchers showed that the most stable isomers of $\mathrm{Mg}^{+}\left(\mathrm{H}_{2} \mathrm{O}\right)_{5}{ }^{5}$ and $\mathrm{Al}^{+}\left(\mathrm{H}_{2} \mathrm{O}\right)_{5}{ }^{31,32}$ cluster ions have a similar structure.

For even larger $\mathrm{Mg}^{+}\left(\mathrm{CH}_{3} \mathrm{OH}\right)_{n}$ cluster ions, although theoretical calculations were not performed due to their large size, their structures may have the same basis as that for the small cluster ions. They may also have three methanol molecules located in the first shell and the fourth methanol molecule starts to fill the second shell. At certain cluster sizes, the second shell is completed and the solvent molecule may start to fill the third shell. The major interactions among neighboring methanol molecules are the hydrogen bonds.

2. Structures of $\mathrm{MgOCH}_{3}{ }^{+}\left(\mathrm{CH}_{3} \mathrm{OH}\right)_{n-1}(\mathbf{1} \leq n \leq 5)$. The optimized structures for $\mathrm{MgOCH}_{3}{ }^{+}\left(\mathrm{CH}_{3} \mathrm{OH}\right)_{n-1}$ where $n \leq 5$ at the SCF/6-31G* level are shown in Figures 14 and 15. The calculated total energies and the relative energies for the isomers of $\mathrm{MgOCH}_{3}{ }^{+}\left(\mathrm{CH}_{3} \mathrm{OH}\right)_{n-1}$ and the zero-point energy corrections for the most stable isomers are listed in Table 3.

$\mathrm{MgOCH}_{3}{ }^{+}$is found to take an optimized structure $\mathbf{I}$ in Figure 14 , which belongs to the $C_{3 v}$ point group. The bond length of $\mathrm{Mg}-\mathrm{O}$ is calculated to be $1.699 \AA$, which is much smaller than that in $\mathrm{Mg}^{+}\left(\mathrm{CH}_{3} \mathrm{OH}\right)$ due to its covalent nature. The charge on magnesium and oxygen atoms is 1.887 and -1.275 , respectively.

Structure II for $\mathrm{MgOCH}_{3}{ }^{+}\left(\mathrm{CH}_{3} \mathrm{OH}\right)$ has both oxygen atoms directly bonded to $\mathrm{Mg}^{+}$. A previous study on $\mathrm{MgOH}^{+}\left(\mathrm{H}_{2} \mathrm{O}\right)$ showed that the structure with $\mathrm{H}_{2} \mathrm{O}$ bonded to the $\mathrm{H}$ in the $\mathrm{OH}$ group is very unstable,,$^{5}$ so we did not consider a similar structure 


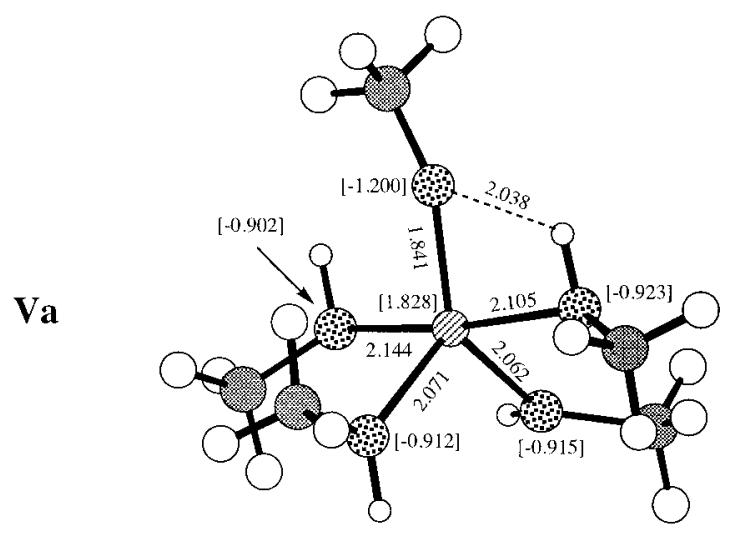

Vb

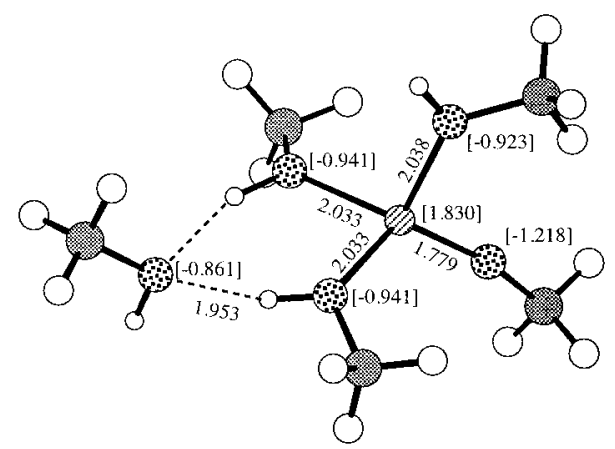

Figure 15. Optimized structures of $\mathrm{MgOCH}_{3}{ }^{+}\left(\mathrm{CH}_{3} \mathrm{OH}\right)_{5}(\mathbf{V a}, \mathbf{V b})$ at the $\mathrm{SCF} / 6-31 \mathrm{G}^{*}$ level. Distances are in angstroms. The values in square brackets indicate the natural charge for the corresponding atoms.

TABLE 3: Calculated Energies for Different Structure for $\mathrm{MgOCH}_{3}{ }^{+}\left(\mathrm{CH}_{3} \mathrm{OH}\right)_{n-1}(n \leq 5)$ at the SCF/6-31G* Level as Well as the Relative Energies for Different Isomers ${ }^{a}$

\begin{tabular}{lcccc}
\hline \multicolumn{1}{c}{ cluster } & structure & $\begin{array}{c}\text { energies } \\
\text { (hartree) }\end{array}$ & $\begin{array}{c}\text { relative } \\
\text { energies } \\
(\mathrm{kJ} / \mathrm{mol})\end{array}$ & $\begin{array}{c}\mathrm{ZPE} \\
\text { (hartree) }\end{array}$ \\
\hline $\mathrm{MgOCH}_{3}{ }^{+}$ & I & -313.817299419 & & 0.044785 \\
$\mathrm{MgOCH}_{3}{ }^{+}\left(\mathrm{CH}_{3} \mathrm{OH}\right)$ & II & -428.949218396 & & 0.102307 \\
$\mathrm{MgOCH}_{3}{ }^{+}\left(\mathrm{CH}_{3} \mathrm{OH}\right)_{2}$ & III & -544.053800392 & & 0.160118 \\
$\mathrm{MgOCH}_{3}{ }^{+}\left(\mathrm{CH}_{3} \mathrm{OH}\right)_{3}$ & IV & -659.143288599 & & 0.217493 \\
$\mathrm{MgOCH}_{3}{ }^{+}\left(\mathrm{CH}_{3} \mathrm{OH}\right)_{4}$ & Va & -774.212217150 & 0 & 0.276108 \\
& Vb & -774.207834400 & 11.52 &
\end{tabular}

${ }^{a} \mathrm{ZPE}$ represents the zero-point energy corrections to the total energies for the most stable isomers.

for $\mathrm{MgOCH}_{3}{ }^{+}\left(\mathrm{CH}_{3} \mathrm{OH}\right)$. In structure II, the $\mathrm{O}-\mathrm{Mg}-\mathrm{O}$ angle is close to $180^{\circ}$. Since $\mathrm{Mg}^{2+}$ does not have the single $3 \mathrm{~s}$ electron as in $\mathrm{Mg}^{+}\left(\mathrm{CH}_{3} \mathrm{OH}\right)_{n}$, the ligand can be evenly located around the central $\mathrm{Mg}^{2+}$. Another feature worthy of note is the smaller $\left(\mathrm{CH}_{3} \mathrm{OMg}\right)^{+}-\mathrm{CH}_{3} \mathrm{OH}$ bond length compared with that in $\mathrm{Mg}^{+}\left(\mathrm{CH}_{3} \mathrm{OH}\right)_{2}$. Clearly, this results from the much stronger interaction between $\mathrm{Mg}$ and oxygen due to the highly polarized $\mathrm{MgOCH}_{3}{ }^{+}$core. The interaction between $\mathrm{Mg}$ and $\mathrm{CH}_{3} \mathrm{OH}$ can still be considered as electrostatic, but is much stronger here due to the double charge of $\mathrm{Mg}^{2+}$. This also applies to larger clusters. In structure III for $\mathrm{MgOCH}_{3}{ }^{+}\left(\mathrm{CH}_{3}{ }^{-}\right.$ $\mathrm{OH})_{2}$, the calculation shows that the distance between $\mathrm{Mg}^{2+}$ and the oxygen atom in $\mathrm{CH}_{3} \mathrm{OH}(1.995 \AA)$ is smaller than that in $\mathrm{Mg}^{+}\left(\mathrm{CH}_{3} \mathrm{OH}\right)_{3}$. Here the three oxygen atoms are almost evenly located around $\mathrm{Mg}$ within the same plane. The angles of $\mathrm{CH}_{3} \mathrm{HO}-\mathrm{Mg}-\mathrm{OCH}_{3}$ and $\mathrm{CH}_{3} \mathrm{HO}-\mathrm{Mg}-\mathrm{OHCH}_{3}$ are close to $120^{\circ}$. The optimized structure VI for $\mathrm{MgOCH}_{3}{ }^{+}\left(\mathrm{CH}_{3} \mathrm{OH}\right)_{3}$ has the three methanol molecules directly bonded to $\mathrm{MgOCH}_{3}{ }^{+}$.
The distances between $\mathrm{Mg}^{2+}$ and the oxygen atoms in methanol are slightly larger than those in smaller clusters due to the increased ligand-ligand repulsion, but they are still smaller than those in $\mathrm{Mg}^{+}\left(\mathrm{CH}_{3} \mathrm{OH}\right)_{4}$.

For larger clusters (e.g., $\left.\mathrm{MgOCH}_{3}{ }^{+}\left(\mathrm{CH}_{3} \mathrm{OH}\right)_{4}\right)$, the question arises again as to whether the second solvation shell has started to form as the ligand-ligand repulsions increase. We investigated two isomers for $\mathrm{MgOCH}_{3}{ }^{+}\left(\mathrm{CH}_{3} \mathrm{OH}\right)_{4}$ shown in Figure 15. Structure Va has all the five oxygen atoms directly bonded to $\mathrm{Mg}$, and the methanol molecules are all located in the first solvation shell. The five oxygen atoms form a nearly trigonalbipyramid structure commonly observed in five-coordination systems. ${ }^{33}$ The oxygen atom in $\mathrm{MgOCH}_{3}{ }^{+}$is located at the vertex of the triangle that bridges the two pyramid structures. This oxygen atom forms a hydrogen bond with a hydroxide group in a methanol molecule nearby. The distance for this hydrogen bond is calculated to be $2.038 \AA$. The distances between this oxygen atom and other $\mathrm{OH}$ groups are all above $2.5 \AA$ and do not form any hydrogen bond. The $\mathrm{Mg}-\mathrm{O}$ distance increases further from that in $\mathrm{MgOCH}_{3}{ }^{+}\left(\mathrm{CH}_{3} \mathrm{OH}\right)_{3}$. For example, the $\mathrm{Mg}-\mathrm{O}$ distance in the $\mathrm{MgOCH}_{3}{ }^{+}$core of $\mathrm{MgOCH}_{3}{ }^{+}\left(\mathrm{CH}_{3} \mathrm{OH}\right)_{4}$ is $1.841 \AA$, that is much larger than that in $\mathrm{MgOCH}_{3}{ }^{+}\left(\mathrm{CH}_{3} \mathrm{OH}\right)_{3}(1.774 \AA)$. Obviously the ligandligand repulsions in structure $\mathrm{Va}$ are much larger than those in smaller cluster systems. Structure $\mathbf{V b}$ has three methanol molecules directly bonded to $\mathrm{MgOCH}_{3}{ }^{+}$, so there are four oxygen atoms in the first solvation shell. The fifth methanol molecule is located in the second shell and it is connected to two methanol molecules in the first shell via two hydrogen bonds. The length of the hydrogen bond is $1.953 \AA$. With these two hydrogen bonds, a six-membered ring structure was formed to stabilize the system. Despite this stabilization, we found that this structure is higher in energy than structure Va by 11.52 $\mathrm{kJ} / \mathrm{mol}$. This is ascribed to the stronger electrostatic interactions between $\mathrm{Mg}^{2+}$ and the oxygen atoms in structure $\mathbf{V a}$ than those in structure $\mathbf{~ V b}$.

We did not proceed the calculations further for even larger clusters, but it is expected that the stable structure for $\mathrm{MgOCH}_{3}{ }^{+}\left(\mathrm{CH}_{3} \mathrm{OH}\right)_{5}$ may still have all the methanol molecules in the first solvation shell. Survey of structural data in various crystals containing divalent magnesium ion shows that, in most cases, the coordination number of magnesium $\mathrm{Mg}^{2+}$ in crystal structures tends to be six. ${ }^{34} \mathrm{Ab}$ initio molecular orbital calculations revealed that the lowest energy configuration of hydrated $\mathrm{Mg}^{2+}$ has six water molecules packed into the inner shell. ${ }^{34}$ For even larger clusters such as $\mathrm{MgOCH}_{3}{ }^{+}\left(\mathrm{CH}_{3} \mathrm{OH}\right)_{6}$, the sixth methanol molecule may start to fill the second shell and be hydrogen bonded to the methanol molecules in the first shell.

It has been shown above that the structures for $\mathrm{MgOCH}_{3}{ }^{+}\left(\mathrm{CH}_{3} \mathrm{OH}\right)_{n-1}$ are significantly different from those of $\mathrm{Mg}^{+}\left(\mathrm{CH}_{3} \mathrm{OH}\right)_{n}$. While the methanol molecules in the latter tend to be located on one side of $\mathrm{Mg}^{+}$, those in the former series can be evenly distributed around $\mathrm{Mg}^{2+}$. The interactions between methanol molecules and $\mathrm{Mg}^{2+}$ in $\mathrm{MgOCH}_{3}{ }^{+}\left(\mathrm{CH}_{3} \mathrm{OH}\right)_{n-1}$ are much stronger than those in $\mathrm{Mg}^{+}\left(\mathrm{CH}_{3} \mathrm{OH}\right)_{n}$ due to the highly polarized $\mathrm{MgOCH}_{3}{ }^{+}$molecular ion core. The charge on $\mathrm{Mg}^{2+}$ in $\mathrm{MgOCH}_{3}{ }^{+}\left(\mathrm{CH}_{3} \mathrm{OH}\right)_{n}(1 \leq n \leq 5)$ is between 1.887 and 1.828 and that on the oxygen atom is about -1.25 . This contrasts sharply with $\mathrm{Mg}^{+}\left(\mathrm{CH}_{3} \mathrm{OH}\right)_{n}$, where the charges on $\mathrm{Mg}$ and the oxygen atoms are in the range of $0.98-0.95$ and of -0.98 to -0.94 , respectively.

3. H-Elimination Energies for $\mathrm{Mg}^{+}\left(\mathrm{CH}_{3} \mathrm{OH}\right)_{n}(\mathbf{1} \leq n \leq$ 5). The calculated energetic information on cluster ions 
TABLE 4. Calculated H-Elimination Energies for $\mathrm{Mg}^{+}\left(\mathrm{CH}_{3} \mathrm{OH}\right)_{n}(n=1-5)$ at the SCF/6-31G* Level ${ }^{a}$

\begin{tabular}{|c|c|c|c|c|}
\hline \multirow[b]{2}{*}{ reactions } & \multicolumn{2}{|c|}{$\Delta E_{0}$} & \multicolumn{2}{|c|}{$\Delta E_{\mathrm{ZPV}}$} \\
\hline & $\mathrm{kcal} / \mathrm{mol}$ & $\mathrm{eV}$ & $\mathrm{kcal} / \mathrm{mol}$ & $\mathrm{eV}$ \\
\hline $\mathrm{Mg}^{+}\left(\mathrm{CH}_{3} \mathrm{OH}\right) \rightarrow \mathrm{MgOCH}_{3}^{+}+\mathrm{H}$ & 82.432 & 3.575 & 74.644 & 3.237 \\
\hline $\mathrm{Mg}^{+}\left(\mathrm{CH}_{3} \mathrm{OH}\right)_{2} \rightarrow \mathrm{MgOCH}_{3}{ }^{+}\left(\mathrm{CH}_{3} \mathrm{OH}\right)+\mathrm{H}$ & 52.009 & 2.256 & 44.010 & 1.908 \\
\hline $\mathrm{Mg}^{+}\left(\mathrm{CH}_{3} \mathrm{OH}\right)_{3} \rightarrow \mathrm{MgOCH}_{3}{ }^{+}\left(\mathrm{CH}_{3} \mathrm{OH}\right)_{2}+\mathrm{H}$ & 31.015 & 1.345 & 23.326 & 1.011 \\
\hline $\mathrm{Mg}^{+}\left(\mathrm{CH}_{3} \mathrm{OH}\right)_{4} \rightarrow \mathrm{MgOCH}_{3}{ }^{+}\left(\mathrm{CH}_{3} \mathrm{OH}\right)_{3}+\mathrm{H}$ & 16.078 & 0.697 & 7.392 & 0.321 \\
\hline $\mathrm{Mg}^{+}\left(\mathrm{CH}_{3} \mathrm{OH}\right)_{5} \rightarrow \mathrm{MgOCH}_{3}{ }^{+}\left(\mathrm{CH}_{3} \mathrm{OH}\right)_{4}+\mathrm{H}$ & 10.051 & 0.436 & 1.258 & 0.055 \\
\hline
\end{tabular}

${ }^{a} \Delta E_{0}$ and $\Delta E_{\mathrm{ZPV}}$ represent the energies without and with zero-point vibration energy corrections, respectively.

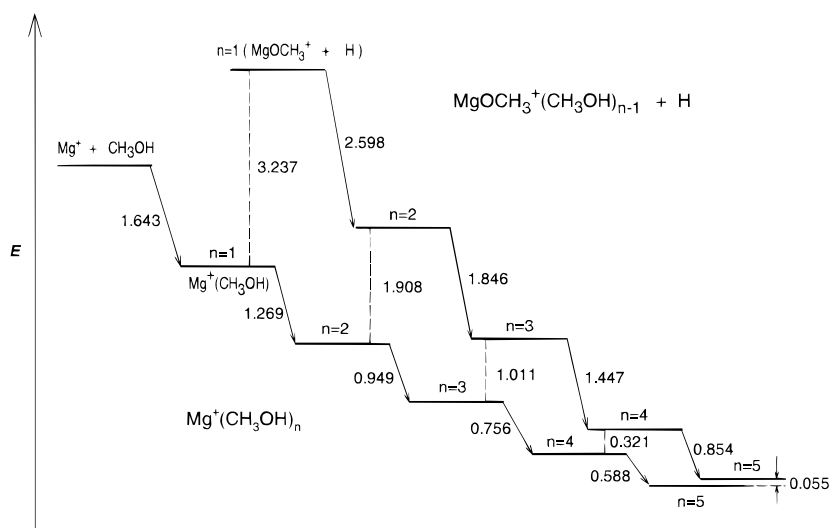

Figure 16. Schematic diagram showing the energy changes $(\mathrm{eV}$, indicated by arrow) of $\mathrm{Mg}^{+}\left(\mathrm{CH}_{3} \mathrm{OH}\right)_{n}$ and $\mathrm{MgOCH}_{3}+\left(\mathrm{CH}_{3} \mathrm{OH}\right)_{n-1}$ with increasing cluster size as well as the $\mathrm{H}$-elimination energies $(\mathrm{eV}$, indicated by dashed line) for $\mathrm{Mg}^{+}\left(\mathrm{CH}_{3} \mathrm{OH}\right)_{n}(n=1-5)$. The values correspond to the data after the zero-point vibration energy corrections.

$\mathrm{Mg}^{+}\left(\mathrm{CH}_{3} \mathrm{OH}\right)_{n}$ and $\mathrm{MgOCH}_{3}{ }^{+}\left(\mathrm{CH}_{3} \mathrm{OH}\right)_{n-1}$ allows us to estimate the energy change for the following $\mathrm{H}$-elimination reaction.

$$
\begin{gathered}
\mathrm{Mg}^{+}\left(\mathrm{CH}_{3} \mathrm{OH}\right)_{n} \rightarrow \mathrm{MgOCH}_{3}^{+}\left(\mathrm{CH}_{3} \mathrm{OH}\right)_{n-1}+\mathrm{H} \\
\Delta E(n)=\left[E^{\prime}(n-1)+E(\mathrm{H})\right]-E(n)
\end{gathered}
$$

where $E^{\prime}(n-1)$ and $E(n)$ refer to the total energies of $\mathrm{MgOCH}_{3}{ }^{+}\left(\mathrm{CH}_{3} \mathrm{OH}\right)_{n-1}$ and $\mathrm{Mg}^{+}\left(\mathrm{CH}_{3} \mathrm{OH}\right)_{n}$, respectively. $E(\mathrm{H})$ represents the energy of the hydrogen atom and is known to be -0.5 hartree. Table 4 lists the calculated $\mathrm{H}$-elimination energies for $\mathrm{Mg}^{+}\left(\mathrm{CH}_{3} \mathrm{OH}\right)_{n}$ evaluated at the $\mathrm{SCF} / 6-31 \mathrm{G}^{*}$ level. Figure 16 shows a schematic diagram for the successive solvation energy changes of $\mathrm{Mg}^{+}\left(\mathrm{CH}_{3} \mathrm{OH}\right)_{n}$ and $\mathrm{MgOCH}_{3}{ }^{+}\left(\mathrm{CH}_{3} \mathrm{OH}\right)_{n-1}$ $+\mathrm{H}$ with the increasing cluster size as well as the $\mathrm{H}$-elimination energies (eV, indicated by dashed lines) for $\mathrm{Mg}^{+}\left(\mathrm{CH}_{3} \mathrm{OH}\right)_{n}(n$ $=1-5)$.

The most immediate observation from the energy diagram is that the $\mathrm{H}$-elimination products $\mathrm{MgOCH}_{3}{ }^{+}\left(\mathrm{CH}_{3} \mathrm{OH}\right)_{n-1}+\mathrm{H}$ are stabilized much more quickly than $\mathrm{Mg}^{+}\left(\mathrm{CH}_{3} \mathrm{OH}\right)_{n}$ with an increasing cluster size. This is due to the much stronger electrostatic interactions between the solvent molecules and $\mathrm{Mg}$ in the former series, which has a polarized ion core $\mathrm{MgOCH}_{3}{ }^{+}$ with a doubly charged ion $\mathrm{Mg}^{2+}$. The difference in solvation energy results in a decrease of the energy differences between the reactants and products with the increasing extent of solvation. For example, the energy difference between $\mathrm{MgOCH}_{3}{ }^{+}\left(\mathrm{CH}_{3} \mathrm{OH}\right)_{n-1}+\mathrm{H}$ and $\mathrm{Mg}^{+}\left(\mathrm{CH}_{3} \mathrm{OH}\right)_{n}$ decreases from $3.237 \mathrm{eV}$ for $n=1-0.055 \mathrm{eV}$ for $n=5$ with ZPV correction. The energies of the two cluster systems at $n=5$ are very close to each other. From our experimental results, the transition (first switching) between the two species occurs at $n=5$ where $\mathrm{MgOCH}_{3}{ }^{+}\left(\mathrm{CH}_{3} \mathrm{OH}\right)_{4}+\mathrm{H}$ is more thermodynamically favorable than $\mathrm{Mg}^{+}\left(\mathrm{CH}_{3} \mathrm{OH}\right)_{5}$. Qualitatively, the agreement of our calculation with the experiment on this switching behavior is quite good considering the level of our calculation. We believe that calculations at higher levels using better basis sets and considering the electron correlation (e.g., at the MP2 or MP4SDTQ levels $)^{5}$ would result in a better agreement with the experimental results. As an example, for the $\mathrm{Ca}^{+}\left(\mathrm{H}_{2} \mathrm{O}\right)_{n}$ system, the energy differences between $\mathrm{Ca}^{+}\left(\mathrm{H}_{2} \mathrm{O}\right)_{n}$ and $\mathrm{CaOH}^{+}\left(\mathrm{H}_{2} \mathrm{O}\right)_{n-1}$ $+\mathrm{H}$ calculated at the MP2 level are generally smaller than that at the SCF level by about $10-15 \mathrm{~kJ} / \mathrm{mol}(0.1-0.15 \mathrm{eV}){ }^{6}$

\section{Discussion}

1. General Considerations. A potential complication for the laser-ablation source is that the laser-ablated metal ions may not necessarily be in their ground electronic states. The first excited state of the alkaline earth metal ions stems from the promotion of the valence electron to the $\mathrm{p}$ - or d-orbitals. It turns out that these $n p$ excited states of the metal ions all have a very short lifetime. For example, the lifetime for $\mathrm{Mg}^{+}\left({ }^{2} \mathrm{P}\right)$ is only $3.7 \mathrm{~ns}^{35}$ Thus, the contribution from these excited states is minimal. Other excited states (e.g., $\left.{ }^{2} \mathrm{D}\right)$ may participate in the H-elimination reactions. While we cannot exclude any possible reaction of these electronically excited state metal ions, we believe that the observed reaction patterns are mainly from the ground-state reaction based on the following considerations.

The metal ions in the excited states should display different reaction behavior compared with that in the ground states. The ground-state reaction of $\mathrm{Mg}^{+}\left({ }^{2} \mathrm{~S}\right)$ with $\mathrm{CH}_{3} \mathrm{OH}$ to form $\mathrm{MgOH}^{+}$ and $\mathrm{CH}_{3}$ is endothermic by $16 \mathrm{kcal} / \mathrm{mol}^{1}$ Such an endothermic reaction is not expected to occur for the ground-state magnesium ion. However, the ions at higher excited states are energetic enough to react with $\mathrm{CH}_{3} \mathrm{OH}$ to produce $\mathrm{MgOH}^{+}$as the lowest excited-state $\mathrm{Mg}^{+}\left({ }^{2} \mathrm{P}\right)$ is $102.2 \mathrm{kcal} / \mathrm{mol}$ higher in energy than $\mathrm{Mg}^{+}\left({ }^{2} \mathrm{~S}\right) .{ }^{23}$ Our experiment did not identify any signals coming from $\mathrm{MgOH}^{+}$. The fact that we only observed the association product $\mathrm{Mg}^{+}\left(\mathrm{CH}_{3} \mathrm{OH}\right)_{n}$ argues against the possibility of the excited-state reactions in our experiments. In addition, for the dehydrogenation reaction of $\mathrm{Mg}^{+}\left(\mathrm{CH}_{3} \mathrm{OH}\right)_{n}$, if the excited-state species $\left(\mathrm{Mg}^{+}\right)^{*}$ were present, the $\mathrm{H}$-elimination reactions would have started at a smaller cluster size. The energy difference between the ground-state $\mathrm{Mg}^{+}\left(\mathrm{CH}_{3} \mathrm{OH}\right)$ and $\mathrm{MgOCH}_{3}{ }^{+}+\mathrm{H}$ is calculated to be $3.237 \mathrm{eV}(74.6 \mathrm{kcal} / \mathrm{mol})$ at the $\mathrm{SCF} / 6-31 \mathrm{G}^{*}$ level. Since the three lowest excited states of $\mathrm{Mg}^{+}\left(\mathrm{CH}_{3} \mathrm{OH}\right)$ are $79.4,83.9$, and $114.5 \mathrm{kcal} / \mathrm{mol}$ higher in energy than the ground-state $\mathrm{Mg}^{+}\left(\mathrm{CH}_{3} \mathrm{OH}\right),{ }^{10}$ the dehydrogenation reaction for $\mathrm{Mg}^{+}\left(\mathrm{CH}_{3} \mathrm{OH}\right)_{n}$ may take place for $n=1$ or 2 with the electronically excited metal ions. However, no significant amount of $\mathrm{H}$-elimination products $\mathrm{MgOCH}_{3}{ }^{+}\left(\mathrm{CH}_{3} \mathrm{OH}\right)_{n-1}$ was detected for $n<5$, and this lends to the support of our hypothesis that electronically excited $\mathrm{Mg}^{+}$ions did not significantly contribute to the $\mathrm{H}$-elimination reaction.

Another problem with our experiments arises from the kinetic energies of the laser-ablated metal ions as they usually have a wide distribution. While the kinetic energies of metal ions produced from laser ablation are generally in the range $0.1-10$ $\mathrm{eV},{ }^{36}$ values as large as $100 \mathrm{eV}$ have been reported depending 
on the experimental conditions, such as laser fluence, materials used, etc. ${ }^{37}$ The abundant energy of ablated species may affect the reaction kinetics dramatically. In particular, endothermic reactions may become accessible with the argument of ion kinetic energy. ${ }^{38}$ Ion beam experiments have demonstrated the effects of kinetic energy on the $\mathrm{M}^{+}+$hydrocarbon reactions (e.g., $\mathrm{C}-\mathrm{C}$ bond activation appears only at high energy while dehydrogenation may be dominant at low energy). ${ }^{39}$ Thus it is necessary to consider in our experiments whether the kinetic energy of the laser-ablated metal ions plays an important role in giving the final product distributions.

The kinetic energies of the laser-ablated alkaline earth metal ions were found to range from 2 to $30 \mathrm{eV}$ under our experimental conditions with a laser fluence of $5 \times 10^{7} \mathrm{~W} / \mathrm{cm}^{2}$. Additional experiments were performed in order to study the effect of metal ion kinetic energy on the final product distribution. In these experiments, the solid target was placed $10 \mathrm{~cm}$ away from the nozzle axis. The metal ions traveled the $10 \mathrm{~cm}$ distance before they collided with the molecular beam. The delay time between the laser firing and the nozzle opening was carefully adjusted to obtain the optimal cluster ion signals. The strongest ion signal was observed at a delay time $\Delta t_{0}$ which corresponds to the peak in the kinetic energy distribution graph $\left(\sim 8-9 \mathrm{eV}\right.$ for $\left.\mathrm{Mg}^{+}\right)$. By changing the delay time from $\Delta t_{0}$, the reaction products from the metal ions of different velocities are detected. For $\mathrm{Mg}^{+}$, cluster ion signals can be observed at delay times in the range from $\Delta t_{0}-10 \mu \mathrm{s}$ to $\Delta t_{0}+10 \mu \mathrm{s}$, which corresponds roughly to a kinetic energy range of $\sim 4-$ $40 \mathrm{eV}$. The critical sizes for both the first and second product switchings remain unchanged when $\Delta t$ varies, although the overall ion intensity may vary significantly. This is consistent with the results on the $\mathrm{Mg}^{+}-\mathrm{H}_{2} \mathrm{O}$ system reported by Fuke et al., where the critical sizes of the product switchings were found to be unchanged within the observed kinetic energy range from 10 to $60 \mathrm{eV}{ }^{3}$ As suggested by the authors for the H-elimination reactions of $\mathrm{Mg}^{+}\left(\mathrm{H}_{2} \mathrm{O}\right)_{n}$, the critical sizes for both product switchings may not be determined by the reaction dynamics but rather by the relative thermodynamic stability of the reactants and products under our experimental conditions. Of course, there are alternate explanations for the insensitivity of the metal ion kinetic energy on the critical sizes of the product switching. First, since the mean free path in the crossing region is in the submillimeter scale, one would expect that the nascent ion kinetic energy will be significantly reduced by colliding with the carrier gas. This is quite similar to the production of cluster anions by injecting electrons into the supersonic jet. ${ }^{40}$ Second, the metal ion kinetic energy may not be effective in promoting the reaction. Instead, much of the kinetic energy may be consumed by evaporating the methanol molecules. Finally, our mass spectrometer may sample preferentially the reaction products originating from the relatively low-energy metal ions.

2. First Product Switching. According to the above discussion, the first product switching occurs when the products $\mathrm{MOCH}_{3}{ }^{+}\left(\mathrm{CH}_{3} \mathrm{OH}\right)_{n-1}+\mathrm{H}$ become more stable than the reactants $\mathrm{M}^{+}\left(\mathrm{CH}_{3} \mathrm{OH}\right)_{n}$. This is borne out by our ab initio calculations, which showed that $\mathrm{MgOCH}_{3}{ }^{+}\left(\mathrm{CH}_{3} \mathrm{OH}\right)_{n-1}$ is stablized much more quickly with increasing cluster size compared with $\mathrm{Mg}^{+}\left(\mathrm{CH}_{3} \mathrm{OH}\right)_{n}$ because of the highly polarized $\mathrm{MgOCH}_{3}{ }^{+}$core. The trend of the relative stability of the two series is quite obvious as seen in Figure 16 for the $\mathrm{Mg}^{+}\left(\mathrm{CH}_{3} \mathrm{OH}\right)_{n}$ system.

The effect of deuterium substitution on the critical size is consistent with the thermodynamic argument for the dehydrogenation reaction. Since $\mathrm{H}$ and $\mathrm{D}$ are electronically identical, the electronic part of the total energies of the related complexes should be equal. The only differences are associated with the masses and are thence primarily with the zero-point vibrational energies. For $\mathrm{Mg}^{+}\left(\mathrm{CH}_{3} \mathrm{OH}\right)_{n}$ and $\mathrm{Mg}^{+}\left(\mathrm{CH}_{3} \mathrm{OD}\right)_{n}$, the number of $\mathrm{OH}(\mathrm{OD})$ bonds in $\mathrm{MgOCH}_{3}+\left(\mathrm{CH}_{3} \mathrm{OH}\right)_{n-1}$ $\left(\mathrm{MgOCH}_{3}{ }^{+}\left(\mathrm{CH}_{3} \mathrm{OD}\right)_{n-1}\right)$ is less than those in $\mathrm{Mg}^{+}\left(\mathrm{CH}_{3} \mathrm{OH}\right)_{n}$ $\left(\mathrm{Mg}^{+}\left(\mathrm{CH}_{3} \mathrm{OD}\right)_{n}\right)$ by one. The energy drop from $\mathrm{MgOCH}_{3}{ }^{+}\left(\mathrm{CH}_{3} \mathrm{OH}\right)_{n-1}$ to $\mathrm{MgOCH}_{3}{ }^{+}\left(\mathrm{CH}_{3} \mathrm{OD}\right)_{n-1}$ is smaller than that from $\mathrm{Mg}^{+}\left(\mathrm{CH}_{3} \mathrm{OH}\right)_{n}$ to $\mathrm{Mg}^{+}\left(\mathrm{CH}_{3} \mathrm{OD}\right)_{n}$. As a result, more methanol molecules are needed to reach the switching point from $\mathrm{Mg}^{+}\left(\mathrm{CH}_{3} \mathrm{OD}\right)_{n}$ to $\mathrm{MgOCH}_{3}{ }^{+}\left(\mathrm{CH}_{3} \mathrm{OD}\right)_{n-1}$ than those needed for the $\mathrm{Mg}^{+}\left(\mathrm{CH}_{3} \mathrm{OH}\right)_{n}$ system. The situation for $\mathrm{Mg}^{+}\left(\mathrm{CD}_{3} \mathrm{OD}\right)_{n}$ is similar to that for $\mathrm{Mg}^{+}\left(\mathrm{CH}_{3} \mathrm{OD}\right)_{n}$. For the $\mathrm{Mg}^{+}\left(\mathrm{CH}_{3} \mathrm{OH}\right)_{n}$ and $\mathrm{Mg}^{+}\left(\mathrm{CD}_{3} \mathrm{OH}\right)_{n}$ systems, however, there should be no isotope effect for the dehydrogenation reaction since no bond breaking or formation process occurs to the methyl group in the reaction.

In connection to the first product switching, we want to mention the recent work by Stace and co-workers on the gasphase chemistry of $\mathrm{Mg}^{+}$and $\mathrm{Mg}^{2+}$ with methanol clusters with a different experiment setup. ${ }^{16}$ Neutral magnesium-methanol clusters were formed through the reaction of the methanol clusters with a magnesium vapor. The clusters were then subjected to $100 \mathrm{eV}$ electron impact ionization. The singly and doubly charged cluster ions $\mathrm{Mg}^{+}\left(\mathrm{CH}_{3} \mathrm{OH}\right)_{n}$ and $\left[\mathrm{Mg}\left(\mathrm{CH}_{3}-\right.\right.$ $\left.\mathrm{OH})_{n}\right]^{2+}$ were generated. They also observed the ion signals corresponding to $\mathrm{MgOCH}_{3}{ }^{+}\left(\mathrm{CH}_{3} \mathrm{OH}\right)_{n-1}$ for $\mathrm{n} \geq 3$ and ascribed them to be the result of the dehydrogenation of $\mathrm{Mg}^{+}\left(\mathrm{CH}_{3} \mathrm{OH}\right)_{n}$. This critical size is then much smaller than what we found in the present work. There are two possible reasons for this discrepancy. First, the electron impact ionization they used is usually considered as a "nonsoft" ionization technique and may therefore result in high internal excitation in the clusters. ${ }^{41}$ The high internal energies of $\left[\mathrm{Mg}\left(\mathrm{CH}_{3} \mathrm{OH}\right)_{n}\right]^{+}$may reduce the critical size from $n \geq 5$ to $n \geq 3$. Second, it is possible that the dehydrogenation products $\mathrm{MgOCH}_{3}{ }^{+}\left(\mathrm{CH}_{3} \mathrm{OH}\right)_{n-1}$ in Stace's experiment are generated from the deprotonation of the doubly charged ions $\left[\mathrm{Mg}\left(\mathrm{CH}_{3} \mathrm{OH}\right)_{n}\right]^{2+}$. Previous studies on doubly charged alkaline earth metal ion-water clusters by Kebarle et al. showed that these cluster ions undergo collision-induced dissociation (CID) and give charge reduction products at low $n .{ }^{42,43}$ For example, the reaction of $\mathrm{Mg}^{2+}\left(\mathrm{H}_{2} \mathrm{O}\right)_{n}$ to give $\mathrm{MgOH}^{+}\left(\mathrm{H}_{2} \mathrm{O}\right)_{k}+\mathrm{H}_{3} \mathrm{O}^{+}$occurs for $n \geq 3$.

One of most elusive aspects about the $\mathrm{H}$-elimination reactions is their mechanism. On the basis of our experimental results and chemical intuition, we believe that the reaction corresponding to the first switching is through a complex mechanism, which is different from that for the reaction of the methanol monomer with $\mathrm{Ca}^{+}, \mathrm{Sr}^{+}$, and $\mathrm{Ba}^{+}$. Initially, the reaction complex is formed and accompanied perhaps by evaporation of solvent molecules. At a certain stage, the electron transfer from the metal center to the methanol molecules must take place, resulting in the H-elimination.

3. Second Product Switching. The second product switching cluster size is found to be shifted by the deuterium substitution as well. For $\mathrm{Mg}^{+}\left(\mathrm{CH}_{3} \mathrm{OH}\right)_{n}$ and $\mathrm{Mg}^{+}\left(\mathrm{CD}_{3} \mathrm{OH}\right)_{n}$, the second product switching occurs at $n=15$. On the other hand, for $\mathrm{Mg}^{+}\left(\mathrm{CH}_{3} \mathrm{OD}\right)_{n}$ and $\mathrm{Mg}^{+}\left(\mathrm{CD}_{3} \mathrm{OD}\right)_{n}$, the second product switching occurs at $n=14$. Replacing the $\mathrm{CH}_{3}$ group with $\mathrm{CD}_{3}$ group in methanol molecules has no effect on the critical size for the second product switching. Thus, the critical size is affected only by the OH/OD exchange as in the first product switching. 
As in the first product switching, we discuss the second product switching based on the assumption that the critical size is determined by thermodynamic factors. Alternatively, one might emphasize the importance of the hydrogen transport or tunneling dynamics in the clusters. For the reaction within such a large methanol cluster as $\mathrm{Mg}^{+}-\left(\mathrm{CH}_{3} \mathrm{OH}\right)_{16}$, methanol molecules surrounding the metal ions may play the role of a solvation cage, which would create an energy barrier along the reaction path for H-elimination. Conceivably, the trapping probability of the eliminated $\mathrm{H}$ atom upon reaction should increase with increasing cluster size. As a result, the $\mathrm{H}$ elimination reaction may be suppressed for sufficiently large clusters. In fact, these two explanations are inter-related since the stability of the H-trapped structure will certainly affect the H-trapping probability.

The key to understanding the second product switching is the structures of the products before and after the product switching. For the first product switching, it is quite clear that the metal ion-solvent cluster structure has turned to the $\mathrm{H}$-elimination products with the formation of a $\mathrm{MOCH}_{3}{ }^{+}$ion core. The second switching is more ambiguous in this regard. Since after the second product switching, the products have the same stoichiometry as that of the association products without $\mathrm{H}$-elimination, one would speculate that their structures may also be the same. However, this seems inconsistent with the thermodynamic reasoning as well as our experimental results. First, consider two energy curves as a function of cluster size: one corresponds to the H-elimination products and the other corresponds to the association products. In the mass region below the critical size for the first product switching, the energies of $\mathrm{MgOCH}_{3}{ }^{+}\left(\mathrm{CH}_{3} \mathrm{OH}\right)_{n-1}$ are higher than those of $\mathrm{Mg}^{+}\left(\mathrm{CH}_{3} \mathrm{OH}\right)_{n}$. Since the energy decrease of $\mathrm{Mg}-$ $\mathrm{OCH}_{3}{ }^{+}\left(\mathrm{CH}_{3} \mathrm{OH}\right)_{n-1}$ is faster than that of $\mathrm{Mg}^{+}\left(\mathrm{CH}_{3} \mathrm{OH}\right)_{n}$ with cluster size, the two energy curves will cross, leading to the first product switching. But if the energies of the products are monotonic and continuous functions of the cluster size, one would not expect the two curves to meet again at a some larger cluster size, which would constitute the second product switching.

Another important clue concerning the product structures after second product switching comes from the deuterium substitution effect. For clusters below the first product switching cluster size, where $\mathrm{MgOCH}_{3}^{+}\left(\mathrm{CH}_{3} \mathrm{OH}\right)_{n-1}$ is higher than $\mathrm{Mg}^{+}\left(\mathrm{CH}_{3}-\right.$ $\mathrm{OH})_{n}$ in energy, replacing $\mathrm{OH}$ by $\mathrm{OD}$ makes the energy difference even larger due to the zero-point energy corrections. It then requires more methanol solvation for the $\mathrm{H}$-elimination reaction to occur. This is what we observed in our experiments. For the second product switching, our experiments showed that the switching cluster size is smaller upon deuterium substitution (from $n=15$ to $n=14$ ). This suggests that the products created after the second product switching may not involve the $\mathrm{H}-\mathrm{O}$ bond severance. The reason is that the deuterium substitution will shift the energy curve of $\mathrm{MgOCH}_{3}{ }^{+}\left(\mathrm{CH}_{3} \mathrm{OH}\right)_{n-1}$ upward relative to the energy curve of $\mathrm{Mg}^{+}\left(\mathrm{CH}_{3} \mathrm{OH}\right)_{n}$ and have no effect on the product energy curve if the $\mathrm{H}-\mathrm{O}$ bond cleavage does not occur. The consequence is that the switching cluster size will be smaller. This fits nicely into the results of our isotope substitution experiments. If, on the other hand, the product structures embody the $\mathrm{H}-\mathrm{O}$ bond cleavage, the deuterium substitution will shift both product energy curves to a similar extent. The net outcome is that the switching point remains the same and there would be no isotope effect for the second product switching in this case.
The above considerations carry two crucial points: (1) the product structures should not involve $\mathrm{H}-\mathrm{O}$ bond cleavage, for example, $\mathrm{MgOCH}_{3}{ }^{+} \mathrm{H}_{2} \mathrm{OCH}_{3}{ }^{+}\left(\mathrm{CH}_{3} \mathrm{OH}\right)_{n-2}$, a similar structure as that proposed for the $\mathrm{Mg}^{+}-\mathrm{H}_{2} \mathrm{O}$ system, ${ }^{3}$ and (2) the product structures should be different from those of the association products $\mathrm{Mg}^{+}\left(\mathrm{CH}_{3} \mathrm{OH}\right)_{n}$. The burning question is then, what are the product structures on earth after the second product switching?

Remember for the first product switching, the reason $\mathrm{Mg}^{+}\left(\mathrm{CH}_{3}^{-}\right.$ $\mathrm{OH})_{n}$ is relatively unstable with increasing cluster size compared with $\mathrm{MgOCH}_{3}{ }^{+}\left(\mathrm{CH}_{3} \mathrm{OH}\right)_{n-1}$ is that $\mathrm{Mg}$ in the former species has a valence electron around it and the oxidation state of $\mathrm{Mg}$ is +1 , while in the latter case $\mathrm{Mg}$ is oxidized to $\mathrm{Mg}^{2+}$. Therefore, the electrostatic interactions between the methanol ligands and the central $\mathrm{Mg}$ ion in the latter complex are much stronger than those in the former complex such that the energy needed for transferring the electron from $\mathrm{Mg}$ to the methanol ligands is sufficiently compensated at a certain cluster size. For the second product switching, we believe that the electron transfer from the $\mathrm{Mg}$ to the methanol ligands did take place as in the first product switching. But in this case, H-elimination does not occur. This is reasonable because the free electron can be stabilized by solvation given sufficient number of methanol molecules. Ultimately, $\mathrm{Mg}$ must exist in the form of $\mathrm{Mg}^{2+}$ in the solution of polar solvents. In addition, this is consistent with the previous inferences that the product structures should have all their $\mathrm{H}-\mathrm{O}$ bonds intact, and they also should be different from those of the association products.

To proceed a step further, we conjecture a two-cage structure for the products beyond the second switching. In this novel structure, one cage is centered on the $\mathrm{Mg}^{2+}$ and the other is around the free electron. For the metal ion $\mathrm{Mg}^{2+}$, since it has an oxidation state of +2 without outer valence electrons, it should be able to have the methanol ligands evenly distributed around $\mathrm{Mg}^{2+}$. The number of methanol ligands in the first solvation shell is expected to be six based on the knowledge on the coordination of $\mathrm{Mg}^{2+}$ in crystal. $^{32}$ The electron transferred from the $\mathrm{Mg}$ is delocalized among the methanol molecules other than the six directly ligated methanol molecules. It forms a solvated cage structure. The structure is expected to be very similar to the solvation cage structure in methanol glass at low temperature. ${ }^{7,44-47}$ The two solvation cages can be connected by intermediate methanol molecules through hydrogen bonds. Clearly, such a structure should be unstable at small cluster sizes because there is not enough methanol molecules to solvate the transferred electron. Only when the cluster reaches a certain size can this structure then compete favorably with that of the H-elimination products. It should be pointed out that for the solvated electron cage, the electron may not necessarily be in the center. Much further work is needed to understand the structure in greater detail.

The two-cage structure is similar to the previously proposed ion-pair structure of $\mathrm{Sr}^{2+}\left(\mathrm{NH}_{3}\right)_{n}{ }^{-} \cdot{ }^{48,49}$ Fuke et al. also proposed such an ion-pair structure for the $\mathrm{Mg}^{+}-\left(\mathrm{H}_{2} \mathrm{O}\right)_{n}$ system as one of the candidates to explain the second switching behavior. ${ }^{3}$ However, the detailed picture for the ion-pair structure has not yet been worked out. The two-cage structure we proposed should be correctly written as $\left[\mathrm{Mg}^{2+}\left(\mathrm{CH}_{3} \mathrm{OH}\right)_{n}\right]\left[\mathrm{e}^{-}\left(\mathrm{CH}_{3} \mathrm{OH}\right)_{\mathrm{m}}\right]$ rather than the simple $\mathrm{Mg}^{+}\left(\mathrm{CH}_{3} \mathrm{OH}\right)_{n}$. Experimentally, there has been no report on the negatively charged methanol clusters in the gas phase. However, for water and ammonia, stable negatively charged cluster ions were observed when the clusters reached a critical size. ${ }^{50,51}$ It is reasonable to expect that such a kind of methanol cluster anions also exists if enough methanol 
molecules are available to solvate the electron, in much the same way as the solvated electrons in low-temperature methanol glass. ${ }^{45}$ Moreover, the two-cage structure is further stabilized by the attractive Coulombic interaction between the two cages.

The electrostatic forces between $\mathrm{Mg}^{2+}$ and polar ligands such as water and methanol correspond to the charge-dipole interactions, which scale as $\left(Z \mu / r^{2}\right)$. The larger the dipole moment of the ligand, the larger the interactions. For the solvated electron, the interactions between the electron and solvent molecules are also of a charge-dipole type. ${ }^{45,52}$ Under the same condition, the complex with solvent molecules of larger dipole moments will be more stable than those with smaller dipole moments. It is known that the dipole moment of methanol is $1.7 \mathrm{D}$ and that of water is $1.85 \mathrm{D}^{23}$ Qualitatively, more methanol molecules may be required to stabilize the two-cage structure for the metal ion-methanol clusters than the number of water molecules, which are needed for the metal ion-water clusters. Experimentally, we found the critical size for the second product switching of the metal ion-methanol cluster system to be $n=$ 15 for bothe $\mathrm{Mg}$ and $\mathrm{Ca}$, which is larger than that of the metal ion-water cluster system (the switching occurs at $n=13$ for $\mathrm{Ca}$ and $n=15$ for $\mathrm{Mg}$ ). This observation seems to be fairly consistent with the charge-dipole nature for the interactions, which is assumed to be operative in the metal ion-solvent cluster systems.

4. Comparison with the $\mathrm{M}^{+-}\left(\mathrm{H}_{2} \mathrm{O}\right)_{n}$ System $(\mathrm{M}=\mathrm{Mg}$ and Ca). The reaction system $\mathrm{M}^{+}-\left(\mathrm{CH}_{3} \mathrm{OH}\right)_{n}$ in the present study is remarkably similar to the $\mathrm{M}^{+}-\left(\mathrm{H}_{2} \mathrm{O}\right)_{n}$ system in the sense that both the first and the second switchings take place in the same cluster size regions. This is surprising considering that, although $\mathrm{CH}_{3} \mathrm{OH}$ and $\mathrm{H}_{2} \mathrm{O}$ are both polar molecules, their solvent cluster structures are expected to be quite different. $\mathrm{H}_{2} \mathrm{O}$ has two identical $\mathrm{H}$-atoms and both can be used for the hydrogen-bonded networks in water clusters, whereas only one $\mathrm{H}$-atom in $\mathrm{CH}_{3} \mathrm{OH}$ can be used for hydrogen bonding. One should note that the structures of the pure solvent clusters are very different from those in $\mathbf{M}^{+}-(\text {solvent })_{n}$ and the solvated $\mathrm{H}$-elimination products. It is the structures of $\mathrm{M}^{+}-(\text {solvent })_{n}$ and the solvated $\mathrm{H}$-elimination products, instead of the pure solvent clusters, that are important in dictating the H-elimination energies. This suggests a plausible explanation for the similarity in the $\mathrm{H}$-elimination patterns between $\mathrm{M}^{+}-\left(\mathrm{CH}_{3} \mathrm{OH}\right)_{n}$ and $\mathrm{M}^{+-}$ $\left(\mathrm{H}_{2} \mathrm{O}\right)_{n}$. This explanation assumes that, in the cluster range of our investigation, only one $\mathrm{H}-\mathrm{O}$ bond of $\mathrm{H}_{2} \mathrm{O}$ is actively involved in the $\mathrm{H}$-bonding in both $\mathrm{M}^{+}-\left(\mathrm{H}_{2} \mathrm{O}\right)_{n}$ and the solvated $\mathrm{H}$-elimination products. The other $\mathrm{H}-\mathrm{O}$ bond, being idle, can be replaced by $\mathrm{CH}_{3}-\mathrm{O}$ without much effect on the cluster structure. This is indeed what we found in our ab initio calculations. The structures of $\mathrm{M}^{+}-\left(\mathrm{CH}_{3} \mathrm{OH}\right)_{n}$ and $\mathrm{M}^{+}-\left(\mathrm{H}_{2} \mathrm{O}\right)_{n}$ are quite similar. They both have three molecules in the first solvation shell; the second shell is attached to the first shell through hydrogen bonding. The structures of the H-elimination products are also similar for the two metal ion-solvent cluster systems.

\section{Summary}

We have presented the results of our studies on the gas-phase reactions between singly charged alkaline earth metal ions $\left(\mathrm{Mg}^{+}\right.$, $\mathrm{Ca}^{+}, \mathrm{Sr}^{+}$, and $\mathrm{Ba}^{+}$) and methanol clusters in a pick-up cluster source. The reaction products are shown to exhibit anomalous size distributions characterized by two product switching cluster size regions, analogous to the reaction behaviors of the alkaline earth metal ion-water cluster systems. The first product switching from $\mathrm{M}^{+}\left(\mathrm{CH}_{3} \mathrm{OH}\right)_{n}$ to $\mathrm{MOCH}_{3}{ }^{+}\left(\mathrm{CH}_{3} \mathrm{OH}\right)_{n-1}$ occurs for $n$ at around 5. The $\mathrm{MOCH}_{3}{ }^{+}\left(\mathrm{CH}_{3} \mathrm{OH}\right)_{n-1}$ species switches back to $\mathrm{Mg}^{+}\left(\mathrm{CH}_{3} \mathrm{OH}\right)_{n}$ for $n$ at around 15 (second switching). The critical sizes for the first and the second switching were found to be affected by the metal and deuterium substitutions. Deuterium substitution on the $\mathrm{OH}$ group is shown to affect the critical sizes for both product switchings, which is explained based on the thermodynamics of the H-elimination reactions.

The reason for the first product switching is ascribed to the different thermodynamic stabilities for the two relevant species with increasing cluster size. In $\mathrm{MOCH}_{3}{ }^{+}\left(\mathrm{CH}_{3} \mathrm{OH}\right)_{n-1}$ cluster ions, $\mathrm{Mg}$ is oxidized to $\mathrm{Mg}^{2+}$ and the strong electrostatic interactions between $\mathrm{Mg}^{2+}$ and the methanol ligands strongly stabilize the system. This is in contrast to $\mathrm{Mg}^{+}\left(\mathrm{CH}_{3} \mathrm{OH}\right)_{n}$, where the oxidation state of $\mathrm{Mg}$ is +1 . The $\mathrm{MgOCH}_{3}{ }^{+}\left(\mathrm{CH}_{3} \mathrm{OH}\right)_{n-1}$ system is stabilized much more quickly than $\mathrm{Mg}^{+}\left(\mathrm{CH}_{3} \mathrm{OH}\right)_{n}$ with the increasing cluster size, and the transition between the two species readily occurs when the cluster reaches the critical size. For the second switching from $\mathrm{MOCH}_{3}{ }^{+}\left(\mathrm{CH}_{3} \mathrm{OH}\right)_{n-1}$ to $\mathrm{M}^{+}\left(\mathrm{CH}_{3} \mathrm{OH}\right)_{n}$ at large cluster sizes, we believe that the later series has a structure different from those of the small cluster ions. These large clusters are assumed to have an ion-pair structure. In particular, we have proposed a two-cage structure $\left[\mathrm{Mg}^{2+}\left(\mathrm{CH}_{3} \mathrm{OH}\right)_{n}\right]\left[\mathrm{e}^{-}\left(\mathrm{CH}_{3} \mathrm{OH}\right)_{m}\right]$, which embodies both ion solvation and electron solvation.

Structures of singly charged magnesium ion-methanol clusters $\mathrm{Mg}^{+}\left(\mathrm{CH}_{3} \mathrm{OH}\right)_{n}$ and their H-elimination products $\mathrm{MgOCH}_{3}{ }^{+}\left(\mathrm{CH}_{3} \mathrm{OH}\right)_{n-1}$ have been studied by ab initio calculations at the $\mathrm{SCF} / 6-31 \mathrm{G}^{*}$ level. The association product series and the $\mathrm{H}$-elimination product series are found to have dramatically different structures. For $\mathrm{Mg}^{+}\left(\mathrm{CH}_{3} \mathrm{OH}\right)_{n}$, the methanol ligands are located on one side of $\mathrm{Mg}$ to avoid the high electron density on the other side resulting from the single valence electron of $\mathrm{Mg}^{+}$. The number of methanol molecules that can be directly bonded to $\mathrm{Mg}^{+}$is affected by the ligand-ligand repulsions and is limited to three. They form the first solvation shell and the fourth methanol will start to fill the second shell. For $\mathrm{MgOCH}_{3}{ }^{+}\left(\mathrm{CH}_{3} \mathrm{OH}\right)_{n-1}$, the methanol molecules can be evenly located around $\mathrm{Mg}$ and the natural charge calculation found the charge of $\mathrm{Mg}$ to be close to +2 . As a result, the electrostatic interactions between $\mathrm{Mg}$ and methanol ligands are much stronger than those in $\mathrm{Mg}^{+}\left(\mathrm{CH}_{3} \mathrm{OH}\right)_{n}$ where the $\mathrm{Mg}$ has an oxidation state of +1 . Consequently, the $\mathrm{MgOCH}_{3}{ }^{+}\left(\mathrm{CH}_{3} \mathrm{OH}\right)_{n-1}$ series is stabilized much more quickly than $\mathrm{Mg}^{+}\left(\mathrm{CH}_{3} \mathrm{OH}\right)_{n}$ with the increasing cluster size. The energy change for the H-elimination reaction of $\mathrm{Mg}^{+}\left(\mathrm{CH}_{3} \mathrm{OH}\right)_{n}$ decreases from $3.237 \mathrm{eV}$ for $n=1$ to $0.055 \mathrm{eV}$ for $n=5$. Qualitatively, this is consistent with our experimental results that $\mathrm{Mg}^{+}\left(\mathrm{CH}_{3} \mathrm{OH}\right)_{n}$ starts to change to $\mathrm{MgOCH}_{3}{ }^{+}\left(\mathrm{CH}_{3} \mathrm{OH}\right)_{n-1}$ for $n=5$. The driving force for the H-elimination reaction appears to be related to the fact that the products are thermodynamically more stable than the reactants at large cluster sizes.

Acknowledgment. This work is supported by a Grant from the Croucher Foundation (Grant CF95/96.SC02). The authors thank Qifei Wu and Rowenna Leung for their assistance in the experiments.

\section{References and Notes}

(1) Yeh, C. S.; Willey, K. F.; Robbins, D. L.; Duncan, M. A. Int. J. Mass. Spectrom. Ion. Processes 1994, 131, 307.

(2) Misaizu, F.; Sanekata, M.; Fuke, K.; Iwata, S. J. Chem. Phys. 1994 100,1161

(3) Sanekata, M.; Misaizu, F.; Fuke, K.; Iwata, S.; Hashimoto, K. J. Am. Chem. Soc. 1995, 117, 747. 9768. 
(5) Watanake, H.; Iwata, S.; Hashimoto, K.; Misaizu, F.; Fuke, K. J. Am. Chem. Soc. 1995, 117, 755.

(6) Watanabe, H.; Iwata, S. J. Phys. Chem. A. 1997, 101, 487.

(7) Zhu, J.; Cukier, R. I. J. Chem. Phys. 1993, 98, 5679.

(8) Ruff, F.; Csizmadia, I. G. Organic Reactions; Elsevier: Amsterdam, 1994; Chapter 9

(9) Operti, L.; Tews, E. C.; Freiser, B. S. J. Am. Chem. Soc. 1988, 110,3847 .

(10) Bauschlicher, C. W., Jr.; Partridge, H. J. Phys. Chem. 1991, 95, 3946.

(11) Bauschlicher, C. W., Jr.; Partridge, H. J. Phys. Chem. 1991, 95 694.

(12) Qian, J.; Midey, A. J.; Donnelly, S. G.; Lee, J. I.; Farrar, J. M. Chem. Phys. Lett. 1995, 244, 414.

(13) Donnelly, S. G.; Schmuttenmaer, C. A.; Qian, J.; Farrar, J. M. J. Chem. Soc., Faraday Trans. 1993, 89, 1457.

(14) Kaya, T.; Horiki, Y.; Kobayashi, M.; Shinohara, H.; Sato, H. Chem. Phys. Lett. 1992, 200, 435.

(15) Harms, A. C.; Khanna, S. N.; Chen, B.; Castleman, A. W., Jr. J. Chem. Phys. 1994, 100, 3540.

(16) Woodward, C. A.; Dobson, M. P.; Stace, A. J. J. Phys. Chem. A 1997, 101, 2279.

(17) (a) Lu, W. Y.; Huang, R. B.; Yang, S. H. J. Phys. Chem. 1995, 99, 12099. (b) Huang, R. B.; Lu, W. Y.; Yang, S. H. J. Chem. Phys. 1995, 102, 189. (c) Lu, W. Y.; Huang, R. B.; Yang, S. H. Chem. Phys. Lett 1995, 241, 373. (d) Lu, W. Y.; Yang, S. H. Int. J. Mass Spectrom. 1998 in press.

(18) Miller, D. R. In Atomic and Molecular Beam Methods; Scoles, G., Ed.; Oxford University Press: New York, 1988; Vol. 1.

(19) Bauschlicher, C. W., Jr.; Langhoff, S. R. In Gas-Phase Metal Reactions; Fontjin, A., Eds.; North-Holland: Amsterdam, 1992.

(20) Frisch, M. J.; Trucks, G. W.; Schlegel, H. B.; Gill, P. M. W.; Johnson, B. G.; Robb, M. A.; Cheeseman, J. R.; Keith, T.; Petersson, G. A.; Montgomery, J. A.; Raghavachari, K.; Al-Laham, M. A.; Zakrzewski, V. G.; Ortiz, J. V.; Foresman, J. B.; Peng, C. Y.; Ayala, P. Y.; Chen, W.; Wong, M. W.; Andres, J. L.; Replogle, E. S.; Gomperts, R.; Martin, R. L.; Fox, D. J.; Binkley, J. S.; Defrees, D. J.; Baker, J.; Stewart, J. P.; HeadGordon, M.; Gonzalez, C.; Pople, J. A.; Gaussian 94, Revision B.3; Gaussian, Inc.: Pittsburgh, PA, 1995.

(21) Glendening, E. D.; Reed, A. E.; Carpenter, J. E.; Weinhold, F. NBO, Version 3.1.

(22) Fukushima, K. Inter. J. Mod. Phys. B 1995, 9, 3625.

(23) Lide, D. R., Eds. CRC Handbook of Chemistry and Physics, 77th ed. CRC Press: London, 1996.

(24) Davis, H. F.; Suits, A. G.; Lee, Y. T.; Alcaraz, C.; Mestdagh, J. J. Chem. Phys. 1993, 98, 9595
(25) Gibson, J. K. Rapid Commun. Mass Spectrom. 1996, 10, 256.

(26) Operti, L.; Tews, E. C.; Mavmahon, T. J.; Freiser, B. S. J. Am Chem. Soc. 1989, 111, 9152.

(27) Murad, E. J. Chem. Phys. 1981, 75, 4080.

(28) Moore, C. M. Atomic Energy levels; National Bureau of Standards: Washington, DC, 1949.

(29) Hashimoto, K.; Morokuma, K. J. Am. Chem. Soc. 1994, 116, 11436.

(30) Barnett, R. N.; Landman, U. Phys. Rev. Lett. 1993, 70, 1775.

(31) Watanabe, H.; Aoki, M.; Iwata, S. Bull. Chem. Soc. Jpn. 1993, 66 3245 .

(32) Watanabe, H.; Iwata, S. J. Phys. Chem. 1996, 100, 3377.

(33) Butler, I. S.; Harrod, J. F. Inorganic Chemistry; Benjamin/ Cummings Publishing Company: Tokyo, 1989; Chapter 12.

(34) Bock, C. W.; Kaufman, A.; Glusker, J. P. Inorg. Chem. 1994, 33 419.

(35) Radtsig, A. A.; Smirnov, B. M. Reference Data on Atoms, Molecules, and Ions; Spring-Verlag: Berlin, 1985.

(36) Gibson, J. K. J. Phys. Chem. 1996, 100, 15688

(37) Kong, H.; Beauchamp, J. L. J. Phys. Chem. 1985, 89, 3364.

(38) Armentrout, P. B.; Georgiadis, R. Polyhedron 1988, 16/17, 1573

(39) Sunderlin, L. S.; Armentrout, P. B. Organometallics 1990, 9, 1248.

(40) See, for example, Alexander, M. L.; Levinger, N. E.; Johnson, M

A.; Ray, D.; Lineberger, W. C. J. Chem. Phys. 1988, 88, 6200.

(41) Mark, T. D. In Gaseous Ion Chemistry and Mass Spectrometry; Futrell, J. H., Ed.; Wiley: New York, 1986.

(42) Blades, A. T.; Jayaweera, P.; Ikonomou, M. G.; Kebarle, P. J. Chem. Phys. 1990, 92, 5900.

(43) Blades, A. T.; Jayaweera, P.; Ikonomou, M. G.; Kebarle, P. Int. J. Mass. Spectrom. Ion. Processes 1990, 102, 251.

(44) Kevan, L. Chem. Phys. Lett. 1979, 66, 578.

(45) Kevan, L. Acc. Chem. Res. 1981, 14, 138.

(46) Kevan, L. Radiat. Phys. Chem. 1981, 17, 413.

(47) Itskovitch, E. M.; Kuznetsov, A. M.; Ulstrup, J. In The Chemical Phyics of Solvation, Part C; Dogonadze, R. R., Kalman, E., Kornyshev, A. A., Ulstrup, J., Eds.; Elsevier: New York, 1988.

(48) Shen, M. H.; Winniczek, J. W.; Farrar, J. M. J. Phys. Chem. 1987, $91,6447$.

(49) Donnelly, S. G.; Farrar, J. M. J. Chem. Phys. 1993, 96, 5450.

(50) Haberland, H.; Bowen, K. H. In Clusters of Atoms, And Molecules II; Haberland, H., Ed.; Spring-Verlag: New York, 1994 and references therein.

(51) Castleman, A. W., Jr.; Bowen, K. H., Jr. J. Phys. Chem. 1996 100,12911 and references therein.

(52) Stampfli, P. Phys. Rep. 1995, 255, 1. 